\title{
Tank Waste Transport, Pipeline Plugging, and the Prospects for Reducing the Risk of Waste Transfers
}

\section{August 2001}

Timothy D. Welch 


\title{
DOCUMENT AVAILABILITY
}

Reports produced after January 1,1996, are generally available free via the U.S. Department of Energy (DOE) Information Bridge:

Web site: http://www.osti.gov/bridge

Reports produced before January 1, 1996, may be purchased by members of the public from the following source:

\author{
National Technical Information Service \\ 5285 Port Royal Road \\ Springfield, VA 22161 \\ Telephone: 703-605-6000 (1-800-553-6847) \\ TDD: 703-487-4639 \\ Fax: 703-605-6900 \\ E-mail: info@ntis.fedworld.gov \\ Web site: http://www.ntis.gov/support/ordernowabout.htm
}

Reports are available to DOE employees, DOE contractors, Energy Technology Data Exchange (ETDE) representatives, and International Nuclear Information System (INIS) representatives from the following source:

Office of Scientific and Technical Information

P.O. Box 62

Oak Ridge, TN 37831

Telephone: 865-576-8401

Fax: 865-576-5728

E-mail: reports@adonis.osti.gov

Web site: http://www.osti.gov/contact.html

This report was prepared as an account of work sponsored by an agency of the United States government. Neither the United States government nor any agency thereof, nor any of their employees, makes any warranty, express or implied, or assumes any legal liability or responsibility for the accuracy, completeness, or usefulness of any information, apparatus, product, or process disclosed, or represents that its use would not infringe privately owned rights. Reference herein to any specific commercial product, process, or service by trade name, trademark, manufacturer, or otherwise, does not necessarily constitute or imply its endorsement, recommendation, or favoring by the United States government or any agency thereof. The views and opinions of authors expressed herein do not necessarily state or reflect those of the United States government or any agency thereof. 


\title{
TANK WASTE TRANSPORT, PIPELINE PLUGGING, AND THE PROSPECTS FOR REDUCING THE RISK OF WASTE TRANSFERS
}

\author{
Timothy D. Welch
}

August 2001

Prepared by the OAK RIDGE NATIONAL LABORATORY

Oak Ridge, Tennessee 37831-6285 managed by UT-BATTELLE, LLC for the U.S. DEPARTMENT OF ENERGY under contract DE-AC05-00OR22725 



\section{CONTENTS}

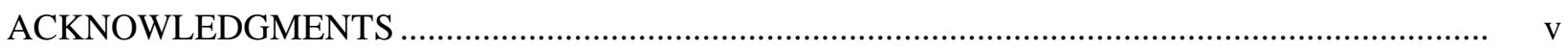

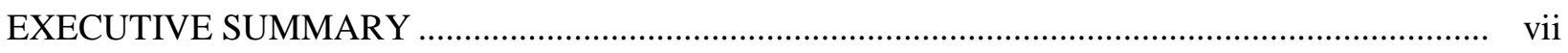

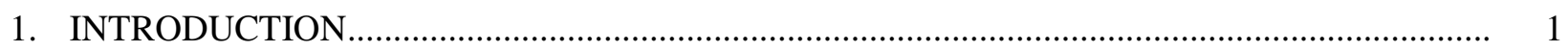

2. PRIMARY CURRENT TANK WASTE TRANSPORT ANALYSIS TOOLS ............................. 3

2.1 WASTE SLURRY TRANSPORT ANALYSIS AT HANFORD ....................................... 3

2.1.1 Critical Velocity and Pressure Drop Calculations ..................................................... 4

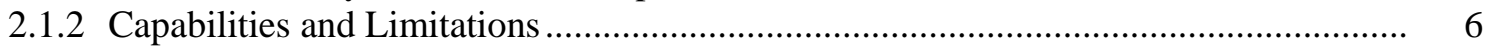

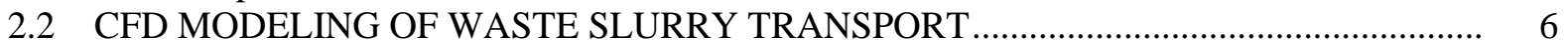

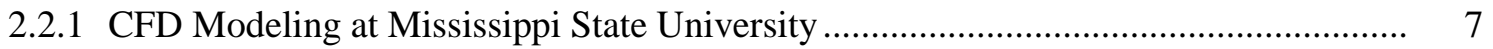

2.2.2 Capabilities, Applications, and Limitations................................................................ 7

2.3 MODELING OF SALT SOLUTION TRANSPORT …..................................................... 8

3. PLUGGING MECHANISMS AND THE COUPLING OF CHEMISTRY

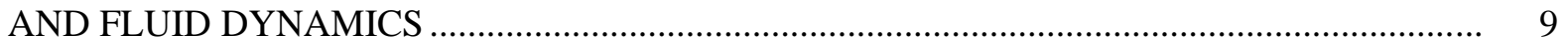

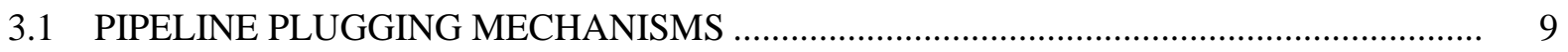

3.2 THE COUPLING OF FLUID DYNAMICS AND CHEMISTRY ..................................... 12

4. PROSPECTS FOR IMPROVED TRANSPORT ANALYSIS TOOLS

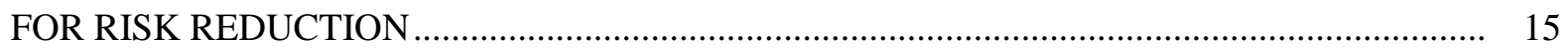

4.1 ASSESSMENT OF EXISTING TOOLS AND PROCEDURES …................................... 15

4.2 CAPABILITIES NEEDED FOR WASTE TRANSFER EVALUATIONS ............................. 16

5. CONCLUSIONS AND RECOMMENDATIONS ............................................................. 19

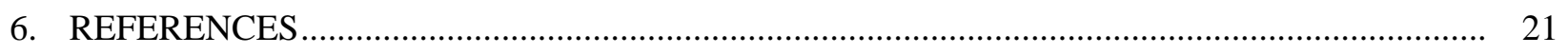

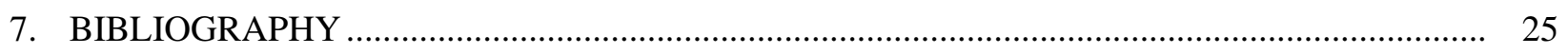

APPENDIX A. THE GILLIES AND SHOOK CRITICAL VELOCITY CORRELATION .................. A-1

APPENDIX B. THE TURBULENT EDDY FRACTION AND HINDERED

SETTLING VELOCITY EQUATIONS FOR THE OROSKAR AND

TURIAN CRITICAL VELOCITY CORRELATION

B-1 



\section{ACKNOWLEDGMENTS}

This work was sponsored by the U.S. Department of Energy through the Office of Science and Technology's Tank Focus Area. Oak Ridge National Laboratory (ORNL) is managed by UT-Battelle, LLC, under contract DE-AC05-00OR22725. I would like to thank my ORNL colleagues Chuck Webber and Rodney Hunt for their helpful discussions of plugging mechanisms and waste chemistry, Jeff Lindner and Hani Alhabbash of Mississippi State University for sharing their insights gained from observations of salt pumping tests and explorations of CFD modeling, Yasuo Onishi of Pacific Northwest National Laboratory for discussions of CFD modeling, and Dan Reynolds of CH2MHILL for his explanations of Hanford operations. I would especially like to thank Jim Jewett of Numatec Hanford Corporation for providing valuable information, Jack Watson, the coordinator of the Efficient Separations and Processing Program, for numerous technical consultations, reviews, and encouragement and Phil McGinnis, the Tanks Focus Area Technical Integration Manager, for his customer-focused perspective in discussions and reviews. 



\section{EXECUTIVE SUMMARY}

This report identifies the fluid dynamics and chemical modeling capabilities needed to reduce the risk of pipeline plugging during tank waste transfers at the U.S. Department of Energy Hanford Site and evaluates some of the relevant modeling tools currently in use for waste transfer analysis. Work needs to be performed to address the limitations of the current models. Development of improved waste transport modeling tools with the capability to describe particle and chemical dynamics, to account for flowchemical coupling, and to account for waste-surface interactions is essential to completely and accurately evaluate the risk of plugging for some waste transfers. Such capabilities will also help the site assess costreduction strategies, develop process control strategies, design transfer piping, and diagnose plugging events.

The report reviews the capabilities and limitations of (1) a critical velocity correlation and (2) a chemical equilibrium model in use at Hanford as well as (3) a three-dimensional computational fluid dynamics (CFD) model that was investigated by Mississippi State University in FY 2000 and FY 2001.

Current analysis of slurry waste transfers at Hanford focus on solids settling from slurries in which the particle-size distribution (PSD) is assumed to be static. An empirical correlation developed by A. R. Oroskar and R. M. Turian in 1980 is used to calculate the velocity required to keep solids suspended. This correlation was developed for slurries with solid characteristics different from those of the Hanford tank wastes - a larger mean particle size, a narrower PSD, a different density, uniform particle shape, etc. Some modifications to correlations are needed to incorporate the effects of PSD and particle shape on hindered settling and slurry viscosity.

Extension and validation of this empirical correlation is necessary to improve the accuracy for slurrywater transfers. The River Protection Project (RPP) and the Tanks Focus Area (TFA) are working to validate and improve these tools for analysis of the static-PSD case.

The Environmental Simulation Program ${ }^{\mathrm{TM}}$ (ESP) is used to estimate the initial waste compositions and solids volume fraction. The TFA is developing data, incorporating this into ESP, and validating ESP with tests on actual wastes.

The possible application of a three-dimensional CFD model has been explored by Mississippi State University Diagnostic and Analysis Instrumentation Laboratory for TFA as an approach to model some dynamic effects in waste transfer analysis, but it was concluded that the considerable expertise and time required to set up a case, the relatively long run times (days) on a Pentium III computer, and the theoretical difficulties in describing the particle-bed dynamics currently limit the applicability of the model for general analysis in the field. CFD will eventually play an increasing role in waste transport analysis as CFD becomes easier to implement, faster computers become available to the design and analysis staff, and theoretical difficulties are overcome. CFD can be productively applied at the present time for some specialized analyses. However, CFD is not likely to supply all the tools needed to meet near-term practical requirements.

Potential plugging mechanisms and dynamic processes that influence pipeline plugging are also discussed. Six distinct and credible waste pipeline plugging mechanisms have been identified. However, the tools currently being used by the site for design and waste transfer evaluations can directly address only one of these-development of a blockage due to solids settling from a slurry with a static PSD. The five additional plugging mechanisms are as follows: 
- settling of solids having a dynamic PSD (as a result of chemical reactions, reaction, precipitation, agglomeration, fragmentation, etc.);

- $\quad$ surface deposition of solids (for static or dynamic PSD) due to adhesion, deposition, or crystal nucleation at the surface;

- bulk or slug plugging, where the entire cross section becomes blocked very rapidly;

- formation of a packed bed at the foot of a vertical pipe leg; and

- solids settling and deposition at dead-flow zones near elbows, flow constrictions, etc.

The model capabilities required to describe and predict these additional mechanisms are outlined in the report.

The static PSD plugging mechanism is relevant for many sludge-water transfers, but models capable of predicting the other five plugging mechanisms are needed. Furthermore, the current waste transfer analysis does not directly consider precipitation, gelation, chemical reaction kinetics, particle agglomeration, particle breakup, and other dynamic processes that occur in some waste transfers. Nor do the current methods account for waste-surface interactions or the coupling of waste chemistry and flow (i.e., how chemistry affects the flow, and how flow affects the chemistry). A model capable of describing these dynamic and coupled processes is essential for predicting four of the six identified plugging mechanisms.

Fluid dynamic forces and changes in the chemical environment can result in dramatic changes in slurry properties and flow behavior during a transfer. Agglomeration and particle breakup due to changes in the chemical environment, particle-particle interactions, shear stresses, precipitation, ordered clustering of solid particles in a flow field, and nonequilibrium thermodynamics can result in waste behaviors not predicted by either equilibrium chemistry or fluid flow alone.

In FY 2002, the TFA is funding a limited effort at Oak Ridge National Laboratory to address some of these waste transport-modeling needs. Practical predictive models that account for chemical-flow coupling and PSD dynamics along the flow route will be developed in an effort to begin to provide some of the capabilities needed to evaluate waste transfers for most of the plugging mechanisms that are not presently being addressed. Transport model development work in FY 2002 will focus on (1) support of salt solution transport projects and operations (e.g., the S-112 project and salt-well pumping) and (2) improvements to the hindered settling correlation to account for settling of polydispersed solids and particle shape. To make the models useful as early as possible in the process, the capabilities of the models will be developed and introduced incrementally. One model will be a laminar flow model with dynamic PSD (mechanism 2) to describe salt solution behavior in pipelines. This model will be applied to the analysis of transfers from trickle-bed saltcake dissolution and salt-well pumping operations. A second model will be a turbulent flow model with dynamic PSD to describe sludge-slurry transfers and saltsolution transfers that are susceptible to bulk plugging. The resulting models will also be applicable to process control, real-time detection and prevention of plugging, diagnosis of plugging events, evaluation of unplugging methods, and process optimization.

RPP and TFA are developing some of the data and data models needed to support these evaluations and models. This work includes collecting data on precipitation and dissolution kinetics, slurry flow studies, salt-well pumping flow studies, measurements of agglomeration and breakup kinetics, viscosity data measurements, and improvements to viscosity and hindered settling models. However, more remains to be done to develop data and models, validate the models, and reduce the calculations to practical tools that can be applied in the field. In addition, simulated waste flow tests in pipeline mockups at Florida International University and Mississippi State University are being conducted to provide data related to slurry transport, salt-well pumping, and saltcake dissolution and transfer. 
Waste transfers should be evaluated using the appropriate predictive tools, results should be validated with tests using simulated and actual wastes, and additional data and model development needs should be identified. It is also recommended that data requirements be assessed to minimize the cost of waste characterization. It is likely that additional kinetic data will be required. In addition to analysis of waste transfers, the application of predictive models to real-time process control and process optimization should be explored. 



\section{INTRODUCTION}

This report provides an overview of the capabilities and limitations of some current models being applied to the analysis of waste transfers; identifies the modeling capabilities needed to reduce the risk of pipeline plugging during tank waste transfers; and summarizes ongoing, planned, and future work needed to add these capabilities. Development of improved waste transport modeling tools with these capabilities will also help with waste transfer planning and evaluation, process control, and diagnosis of plugging events. Other potential applications include evaluation of waste-mixing scenarios, analysis of waste transfer stability, analysis of waste-unplugging alternatives, minimization of water addition, maximization of system availability, evaluation of risk-reduction strategies, and evaluation of cost-reduction strategies.

At the U.S. Department of Energy (DOE) Hanford Site, 55 million gallons of radioactive wastes is stored in 177 underground storage tanks (149 single-shell tanks and 28 double-shell tanks). The wastes in the tanks include insoluble sludge; saltcake precipitated from salt solutions; and liquid supernatant that are typically salt solutions. To treat this waste and put it in a form suitable for final disposition, the waste must be retrieved from the tanks and transported to other tanks for interim storage or waste staging or directly to a waste treatment facility. Several types of transfers take place:

- pumping of supernatant liquids from above the layer of settled solids (decanting);

- pumping of interstitial liquid from the pore spaces in the saltcake layer ("salt-well pumping," also referred to as "interim stabilization");

- pumping water that results from dissolution of the saltcake; and

- pumping of sludge-water, sludge-supernatant, and sludge-salt-supernatant slurries.

Plugging of waste transfer pipelines has occurred occasionally during waste transfers of both salt solutions and sludge slurries. This plugging has been attributed to a variety of causes:

- $\quad$ settling of solids because the flow rate was too low or the solids volume fraction was too high;

- operational upsets-interruption of the waste flow, inadvertent entrainment of solids in the feed, and changes in environmental temperature;

- chemical instability - precipitation, gel formation, or other transformations due to temperature changes, local concentration changes, or mixing and pumping of several wastes that are not in equilibrium;

- hydrodynamic instability - transition of the flow from one flow regime to another (turbulent to laminar) or from one flow pattern to another (homogeneous to heterogeneous) as a result of an external change or as a result of changes in slurry properties occurring during transit;

- piping components that are prone to solids deposition-sharp bends such as those found in Hanford PUREX connectors, unheated jumpers, flow restriction, etc.;

- deposition of solids; and

- crystal growth on surfaces.

At Hanford the Environmental Simulation Program ${ }^{\mathrm{TM}}$ (ESP) is used to estimate the initial composition and the solids content for salt-solution transfers.

Then semiempirical fluid mechanics correlations are used to calculate flow velocities and pressure drops for waste transfers. These tools are used in tandem to evaluate waste transfers, plan for waste feed preparation and delivery, and design piping systems. 
Some of the limitations of ESP and the critical velocity correlation have been identified by the River Protection Project (RPP) and the Tanks Focus Area (TFA), and work is ongoing to address some of these issues. The ESP data are being extended to include more of the solid phases that have been identified in tank waste, such as double salts. The RPP and TFA are conducting tests to obtain the data needed to extend the critical velocity correlation to solids that have a broad particle-size distribution (PSD) similar to that which has been measured for tank waste.

Computational fluid dynamics (CFD) is a third approach being applied to waste problems at Hanford. The Mississippi State University Diagnostic Instrumentation and Analysis Laboratory (MSU-DIAL) is exploring CFD simulations for tank waste transport analysis as well as applying CFD to perform "numerical experiments" to evaluate and extend the baseline correlations. CFD is also being applied at Pacific Northwest National Laboratory (PNNL) to analyze tank waste mixing and retrieval. Onishi et al. (1999) have developed the ARIEL code for this application, which accounts for aqueous chemical reactions, dissolution, precipitation, and rheological changes.

The exact location of the operating envelope boundary that defines a stable waste transfer for a particular waste is uncertain. Site waste transport criteria, the working definition of the operating envelope, have been developed based primarily on fluid dynamics considerations. But uncertainties in the operating envelope boundary come from several sources: the waste characterization data, the fluid dynamics behavior, the chemical dynamics, properties, and limitations in our model's ability to describe these phenomena accurately.

It is essential to have appropriate high-quality data and data models in order to validate models and to apply them in the field. On the other hand, a good model helps identify exactly what data needs to be collected. Thus, data and models complement each other, and it is best to develop them in parallel. The RPP and TFA have ongoing work to measure viscosity, solid densities, PSDs, and other waste properties as well as kinetic parameters for dynamic processes such as precipitation and particle agglomeration. Flow tests are also being conducted using simulated wastes to obtain data relevant to flow-chemistry coupling. The status of data models needed to support waste transport models will be considered in a future report.

Section 2 provides an overview of some current tools for waste transport analysis. First the capabilities and limitations of empirical correlation in use at Hanford are discussed. Section 2 also describes the CFD model being used at MSU-DIAL to simulate waste transport and to evaluate and extend the baseline correlations. The uses and limitations of ESP chemical equilibrium modeling in waste transport evaluations are also briefly discussed. In Sect. 3, credible mechanisms for pipeline plug formation are described and some of the implications of the coupling of chemistry and fluid flow are introduced. In Sect. 4, the implications of these mechanisms and coupling for transport modeling requirements and the prospects for improved transport analysis tools for risk reduction are discussed. Section 5 lists recommendations for developing the tool kit needed to help ensure stable and optimized waste transfer operations. Some related literature not cited in the references is included in a bibliography as Sect. 7 of this report. 


\section{PRIMARY CURRENT TANK WASTE TRANSPORT ANALYSIS TOOLS}

The methods of analysis discussed in Sect. 2 can be mapped in "fluid flow-chemical dynamics" space, as shown in Fig. 2.1. These methods appear on either the chemistry axis (ESP) or the fluid dynamics axis $\left(v_{c}\right.$ and CFD). Each of these models serves a useful but limited role in the design, planning, or analysis of waste transfers. Along the fluid dynamics axis, more detailed information on the pressure, velocity, and local solids buildup is obtained. Along the chemistry axis, ESP gives the equilibrium composition and solids content but provides no information on the rate of solids formation or the concentration along the transfer route. Nor does ESP describe the concentration of intermediates or metastable states anywhere in the waste transfer pipeline. Tank waste mixing studies conducted by Onishi et al. (1999) includes CFD and some chemistry.

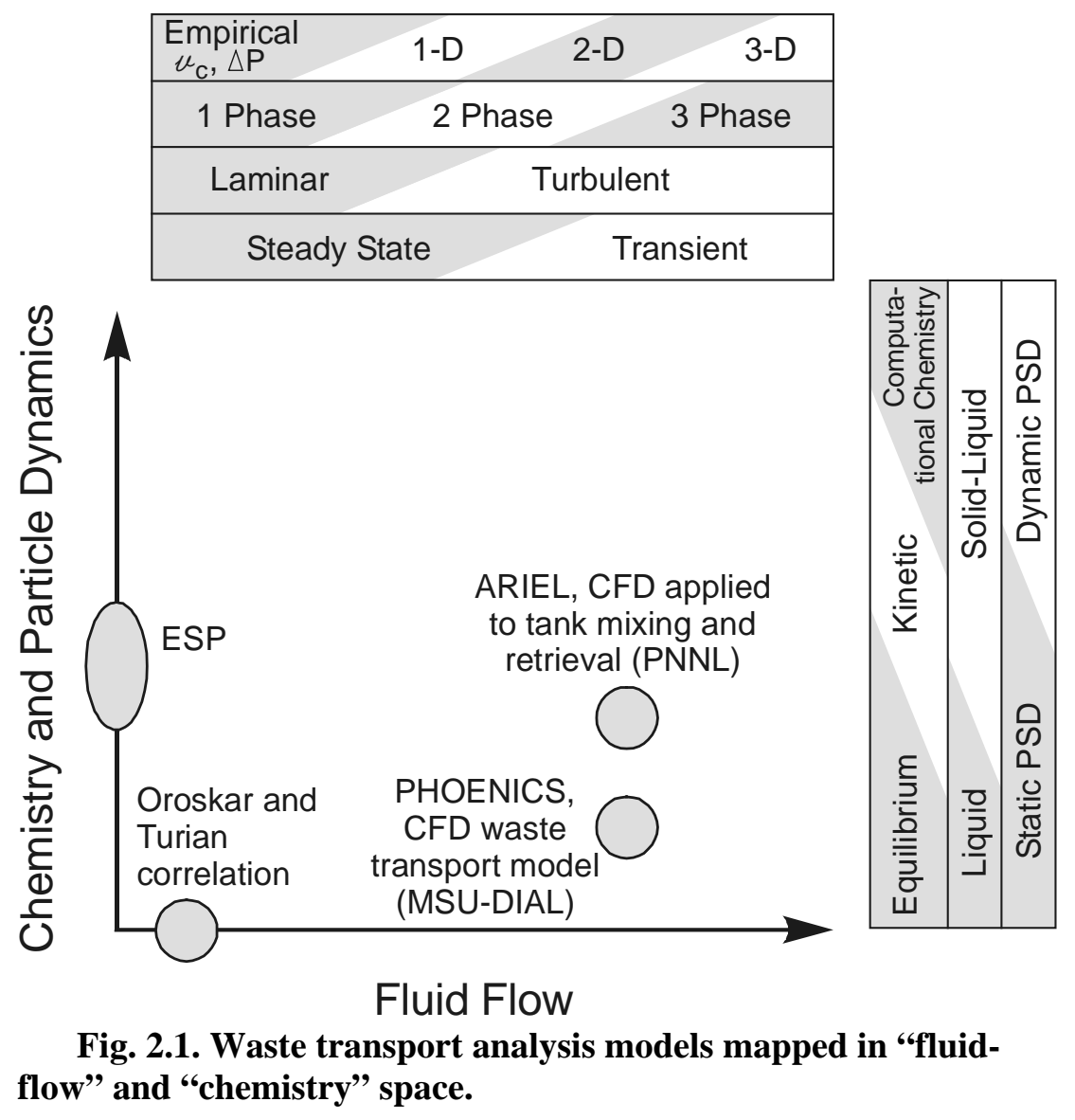

We begin by discussing some of the analysis tools currently in use to predict the critical velocity of a slurry and to calculate the solids content of a salt solution. Explorations of CFD at MSU-DIAL are also discussed.

\subsection{WASTE SLURRY TRANSPORT ANALYSIS AT HANFORD}

This section describes some of the capabilities and limitations of several of the empirical correlations in use at Hanford to calculate the critical flow velocity, that is, the velocity needed to keep solid particles 
suspended in a slurry. The solid-liquid mixtures comprising tank waste slurries may be salt-supernatant, sludge-water, sludge-supernatant, or sludge-salt-supernatant.

Hanford waste transfer criteria limit the slurry solids content to less than 30 vol \% and require a Reynolds number $(\mathrm{Re})$ of greater than 20,000 (Estey and $\mathrm{Hu} 1998$ ) to remain within the piping pressure rating and to prevent solids from settling in the transfer line. In practice, a minimum average velocity of $6 \mathrm{ft} / \mathrm{s}$ and a maximum specific gravity (1.41) are used. These criteria assume that the solids in the slurry do not change during the transfer (i.e., that they are static), are based on steady-state fluid flow, and do not consider the consequences of chemical processes such as precipitation. If solids are formed during the transfer due to chemical processes, the volume percent of solids increases and the Re value decreases, possibly moving outside the criteria limits.

\subsubsection{Critical Velocity and Pressure Drop Calculations}

When calculating the critical velocity, the initial solids volume fraction must be specified. The initial solids volume fraction might be based on the waste transfer criteria; an operating procedure; or in the case of salt solutions, data from laboratory tests or prediction from ESP chemical equilibrium calculations. The solids volume fraction, solid and liquid physical properties, transport properties, pipe dimensions, etc., are then used to calculate the critical velocity and the pressure drop.

Slurries can be classified as settling or nonsettling. The slurry is considered nonsettling for the purposes of the transfer if the solid particles it contains are sufficiently fine and their settling rate is very low relative to the transfer time. The solid particles are assumed to be in a homogeneous suspension. The slurry can be treated as a homogeneous liquid but with the density and viscosity adjusted to account for the presence of the suspended particles. Settling slurries can be classified into three flow patterns: heterogeneous, sliding bed, and stationary bed. An asymmetric vertical solids concentration profile (higher concentration at the bottom) develops as the slurry flow rate is decreased. This is called heterogeneous flow. At lower flow rates, the coarser fraction tends to settle to the bottom, but the solids slide along the bottom - creating a sliding bed. At still lower flow rates, a stationary bed forms. In the latter case, the average velocity of the liquid is greater than the average velocity of the solids. The slip velocity is the difference between the average liquid velocity and the lower average solids velocity.

Settling slurry transfers usually occur in the heterogeneous regime. If the PSD of the slurry solids is broad, the slurry is often modeled as a homogeneous slurry of liquid and very fine particles, called the carrier fluid, and a heterogeneous slurry comprised of the coarser particles and carrier fluid.

Liddell and Burnett (2000) have recently published a comprehensive literature review for the Hanford RPP on critical transport velocity correlations and models. They adopt the following definition for the term critical velocity: "slurry transport at the lowest velocity that prevents deposition of either a stationary or a moving bed of solids." The review indicates that most of the experimental data upon which these correlations are based were obtained for heterogeneous slurries with solids having relatively large $(150-\mu \mathrm{m})$, but narrowly graded, particles size. On the other hand, the Hanford tank solids that have been examined (Jewett and Jensen 2000) appear to have a broad PSD with a mean particle size of $110 \mu \mathrm{m}$ and a substantial fraction of the particles being less than $100 \mu \mathrm{m}$. This suggests that the tank waste be modeled as settling flow (the large particles) with a homogeneous carrier fluid (the carrier liquid plus the fine particles). Since both the mean particle size and the PSD of the tank wastes are different from those of the slurries used to derive the correlations in the literature, application of these to tank wastes is an extrapolation.

Liddell and Burnett conclude that the equations of Oroskar and Turian (1980) and of Gillies and Shook (1991) are the best candidates for tank waste pipeline design, with the caveat that any current literature 
correlation be validated first with experimental data for slurries that are representative of tank wastes. The former equation was recommended because the data used to develop the correlation regression parameters included some particles in the $100-\mu \mathrm{m}$ range. A problem in applying this correlation to tank wastes is that the particles had monodispersed or narrow PSDs. Based on a recent evaluation of particle-size data for Hanford tanks (Jewett and Jensen 2000) for which the data are thought to be most reliable, the particle sizes ranged from 5 to $592 \mu \mathrm{m}$ with a median of $110 \mu \mathrm{m}$. The latter correlation was recommended as a possible option because it was developed for particles with a broad PSD. (The Gillies and Shook correlation is presented in Appendix A.) An earlier analysis of seven critical velocity correlations from 1953 to 1980 by Estey and Hu (1998) recommended the Oroskar and Turian (1980) correlation because it yields the most conservative results.

Recent pipeline hydrodynamic analyses at Hanford have used the correlation of Oroskar and Turian (1980):

$$
v_{c}=1.85 \sqrt{g d(s-1)} C^{0.1536}(1-C)^{0.3564}\left(\frac{d}{D}\right)^{-0.378} \bar{N}_{\operatorname{Re}}^{0.09} x^{0.30}
$$

where

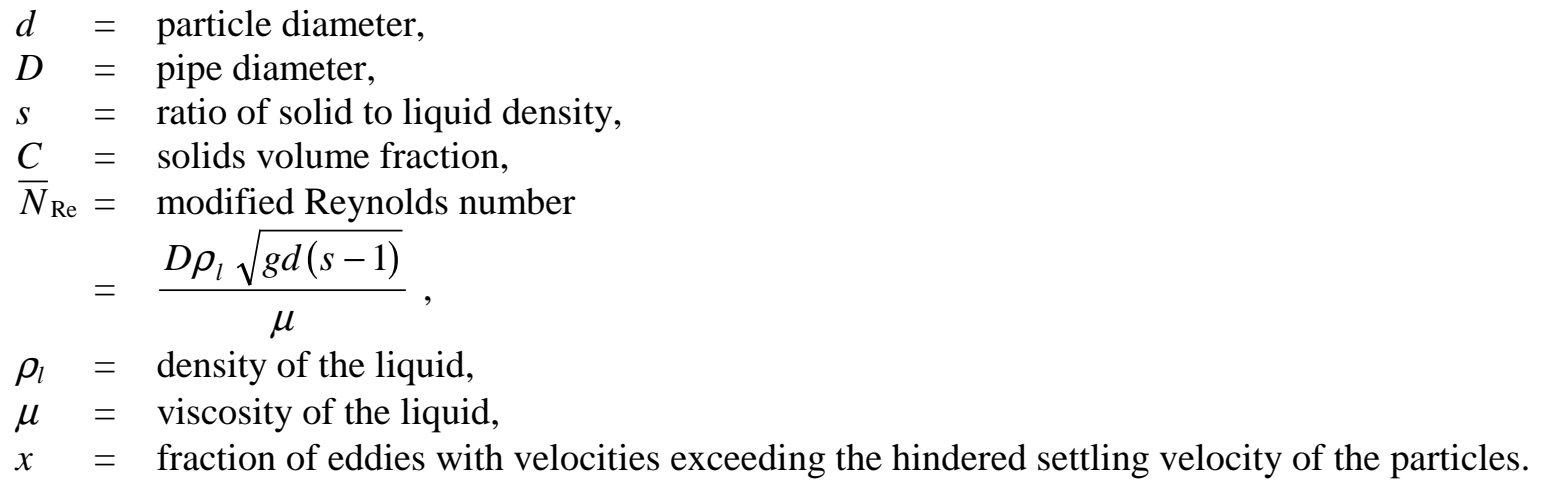

The form of the equation was patterned after a semiempirical equation derived by making a number of limiting assumptions. The $\sqrt{g d(s-1)}$ term is a modified velocity that considers the effect of gravity on the buoyancy forces on the particle. Most of the properties in the equation are relatively easily measurable, except for $x$. This parameter depends on the hindered settling velocity of the particle (see Appendix B). Analyses have used expressions for hindered settling derived from Richardson and Zaki (1954) for monodispersed spherical particles. The Richardson and Zaki equation is not accurate for polydispersed and nonspherical particles.

In an analysis of the Hanford waste feed delivery transfer system, Julyk et al. (2000) describe in detail procedures used to calculate critical velocity and pressure loss. The Oroskar and Turian (1980) critical velocity correlation was used to calculate the minimum waste transport velocity, and the pressure drop was calculated using correlations in Wasp et al. (1979) that had been modified to account for nonhorizontal pipes. Their analysis indicates that settling of solids would occur in many of the Hanford transfer routes. They recommend that several actions to increase pressure ratings be investigated, that particle-size data be critically evaluated, that slurry properties (e.g., solids volume) that increase the pressure drop be restricted, and that critical velocity and pressure drop correlations be validated with simulants or Hanford wastes. 


\subsubsection{Capabilities and Limitations}

The baseline correlations described above are applicable to the flow of heterogeneous slurries of singlesized spherical particles. The Oroskar and Turian correlation estimates one critical velocity for the length of pipe being considered. The physical properties, transport properties, PSD, and temperature are assumed to be the same for the entire length of the pipeline. No information is provided about the local velocity profile, the local solid bed depth, the local liquid concentration, the solids volume fraction, the solids PSD, or the temperature, etc., along the length of the pipe. Nor does it describe how these quantities change with time.

The following summarizes some of the limitations of the critical velocity correlation of Oroskar and Turian, which have been identified in previous reviews (Liddell and Burnett 2000; Estey and Hu 1998) as well as a few additional issues.

Extrapolating beyond range of the original mean particle size and PSD data. Liddell and Burnett (2000) conclude that ". . . there is no published empirical critical velocity equation that is directly applicable to Hanford tank waste slurries." The existing correlations, with the exception of that of Gillies and Shook (1991), were regressed from data for slurries with narrow size distributions and a mean particle size of $100 \mu \mathrm{m}$ or larger. Jewett and Jensen's (2000) analysis of the best available data for Hanford tanks indicated a broad PSD with a significant fraction below $100 \mu \mathrm{m}$. Liddel and Burnett recommended that the correlations be validated by experimental work.

Hindered settling. Oroskar and Turian (1980) explicitly account for hindered settling in their correlation by incorporating the relationship described by Maude and Whitmore (1958), which is similar to the Richardson and Zaki equation (1954). However, this equation fails for polydispersed and nonspherical particles. Accounting for hindered settling, a strongly nonlinear function of solids volume fraction, PSD, and particle shape is essential for accurate predictions in all but the most dilute slurry. Work is ongoing at Florida International university (FIU) to obtain experimental data to check the correlation.

Slurry viscosity. The viscosity depends on volume percent solids, particle size, PSD, and particle shape. Slurry viscosity data and viscosity models that account for these factors are needed for homogeneous slurries. The carrier fluid viscosity and the particle settling velocity must either be measured for the specific conditions under consideration or estimated by a model.

Static particle-size distribution. The critical velocity correlations that have been considered assume that the PSD is static; that is, it does not change in transit. For some types of wastes, such as sludges and salt slurries, the PSD changes during transfer due to precipitation, particle breakup, particle agglomeration, settling, or interactions with surfaces. Pipeline plugging is fundamentally a transient process in one-, two-, or three-dimensional space, depending on the particular plugging mechanism. For slurries with dynamic PSDs, the Oroskar and Turian correlations might still be used for predicting the critical velocity if the particle dynamics are slow [Damköhler number $(\mathrm{Da})<<1$ ] or very fast $(\mathrm{Da}>>1)$ relative to the transport times. If the purpose of the analysis includes dynamic process control, investigation of plug formation, or evaluation of unplugging methods, then the transient case must be considered as well.

\subsection{CFD MODELING OF WASTE SLURRY TRANSPORT}

Use of CFD for waste transport modeling is at the opposite end of the spectrum of rigorous physics and complexity from the simpler, empirical approach based on bulk constant properties discussed previously. In the CFD approach, the Navier-Stokes equations are solved numerically to compute the velocity distribution and pressure profile of the slurries over space and time. In addition, the local particle 
concentration, particle-size distribution, solids deposition, and physical and transport properties can be computed by incorporating kinetic models for chemical reactions, precipitation, agglomeration, and other processes. The possibilities of this approach include a case-by-case description detailed in space and time of the slurry flow, plug formation, and unplugging. But simplifications are still required for this approach to be practical. The goal was to be able to define and run a case in a few days using computers that would be available to design and analysis staff. The challenge is to identify those simplifying assumptions that will permit practical solutions to real problems while still capturing the essential physics and chemistry. [See Kuipers and van Swaaij (1998) for a review of the state of the art of CFD in chemical engineering.]

\subsubsection{CFD Modeling at Mississippi State University}

The TFA has supported Mississippi State University (MSU) investigations of the application of CFD to slurry transport and pipeline plugging in FY 2000 and FY 2001. The MSU studies in this area are being conducted by J. Lindner and $\mathrm{H}$. Alhabbash. MSU evaluated commercial and DOE CFD codes for their initial explorations and selected the commercial code PHOENICS. The selection criteria that favored PHOENICS included (1) open access to the source code, (2) technical support, (3) geometry preprocessing, (4) multiple turbulence models, (5) and multiphase capabilities.

In their initial explorations, MSU has made the following assumptions. (1) Rather than tracking individual particles in solid-liquid flow, the interphase slip algorithm is implemented to approximate solids motion (Travis 1985). (2) Precipitation kinetics are not included.

MSU is employing this code to compute the critical velocity and stationary bed profiles as a function of the flow velocity, PSD, solid and liquid densities, viscosity, and volume percent solids. These results will be reduced to a response surface and compared with empirical correlations for the critical velocity. In addition, the code has been used to compare computed pressure drop-velocity relationships with experimental data on simulated tank wastes from FIU. By performing "numerical experiments" with the CFD code, the validity of assumptions used in the empirical correlations can be evaluated and improved correlations can then be developed.

\subsubsection{Capabilities, Applications, and Limitations}

CFD has the potential to provide the relevant engineers (design, field, and control) with important new capabilities such as axial velocity, pressure, and settled bed profiles. When coupled with kinetics of precipitation, agglomeration, and fragmentation, CFD may also be useful for predicting local solids concentration, PSD, and transient pressure and flow signatures.

However, the implementation of CFD modeling also has limitations:

- Constructing the computational mesh for complicated pipe geometries can be time-consuming.

- The time to run individual cases can take days on a Pentium III dual-processor workstation.

Some outstanding issues with the application of CFD to slurry transport include the following:

- The accuracy of the approximations used for solid-liquid flow, especially for concentrated $(>0.1 \%$ solids) slurries, remains problematic. For dense suspensions, four-way coupling is present; that is, the fluid flow affects particle motion, the particle motion affects fluid structure, and particles interact with other particles (e.g., Levenspiel 1962). 
- Describing the physics of the settled bed dynamics is very difficult; thus, simplifying assumptions must still be made when applying CFD.

- The chemical kinetics that are included must be relatively simple so that problems can be solved in a reasonable time.

For these reasons, the work on CFD to support immediate site waste transport needs is being put on hold by the TFA in FY 2002. CFD will eventually play a role in the analyst's tool kit for specialized applications, as CFD becomes easier to implement, faster computers become available to the design and analysis staff, and theoretical difficulties are overcome. In Sect. 4, a model development approach is proposed that addresses some of these difficulties and lays the groundwork for future CFD implementation.

\subsection{MODELING OF SALT SOLUTION TRANSPORT}

The RPP and the TFA have done a great amount of work over the last few years to validate and enhance ESP, a computer code that models the equilibrium chemistry of electrolyte solutions. ESP predicts the liquid-phase composition, the solid phases that are formed, and the quantity of solids formed for an input composition. The ESP code has been used for a number of applications at Hanford. These applications include estimating the compositions and phases of waste mixtures for feed preparation, estimating the dilution water required for dissolving saltcakes, and estimating the dilution required for salt-well pumping.

Our purpose here is to highlight how ESP is applied to estimate the initial conditions (composition and solids content) of a salt-solution transfer and to summarize ESP's capabilities and limitations with respect to tank waste transport analysis. A detailed discussion of this work on ESP is beyond the scope of this report. For examples of recent work related to ESP, see Herting (2000a, 2000b), Herting et al. (1999), Toghiani and Lindner (2001), Toghiani et al. (2000), Orme (1999), and Garfield et al. (2000).

Salt solution may be pumped from tank salt wells, from saltcake dissolution operations, or as the slurry carrier liquid for transporting sludge. The solution may be nearly saturated, and in many cases, the flow is in the laminar regime. ESP is used to estimate how much dilution water must be added so that the solids content is low enough to meet waste transfer criteria. If the salt solution has few solids $(<0.1 \%)$, the solution is typically considered to be a liquid for purposes of hydraulic analysis and standard methods for liquids are then applied. The maximum quantity and the type of solids that may form due to cooling during transport or other process upsets may also be calculated prior to a transfer by a chemical equilibrium code such as ESP.

In addition to equilibrium calculations, ESP can perform calculations for some unit operations that require kinetic data (e.g., reactors). This capability has not been used for waste transport calculations, in part because of the lack of the kinetic constants that are needed and because of the limited number of unit operations models that are available. Furthermore, these unit operation models are restricted to modeling steady-state operation.

Data for some of the solids that have been found in the tank wastes are not in the ESP data base. TFA is working to incorporate some of this additional data and to validate the code against simulated wastes and actual wastes. An issue here is the identification of the most important reactions and phases for which to obtain data. ESP does not account for other dynamic processes that may be important in slurry transfers (e.g., breakup of colloidal particles or agglomeration of particles to form particles or metastable gels). 


\section{PLUGGING MECHANISMS AND THE COUPLING OF CHEMISTRY AND FLUID DYNAMICS}

Hanford's waste transfer criteria are based primarily on fluid dynamics considerations. The volume fraction of solids is limited to $30 \mathrm{vol} \%$ so that the slurry viscosity and the pressure required to pump the slurry do not become too high. A minimum velocity is specified to keep slurry solids suspended during transfer. ESP is used to predict the initial solids fraction of solids and slurry properties. The criteria are designed to provide a slurry that is pumpable and stable with respect to settling. But settling is only one of several plugging mechanisms that has been observed, suspected, or postulated based on assessments of plugging events.

To adequately assess the stability of a waste transfer, the credible plugging mechanisms for that transfer must be evaluated. Most sludge-water transfers could probably be safely accomplished by operating within the fluid dynamics-based transfer criteria, but operating experience suggests that the same is not true for all waste transfers. We would like to identify these potentially problematic waste transfers in advance so that stable transfer conditions can be specified.

This section introduces some of the factors that may need to be considered in order to assess the stability of waste transfers and to more accurately determine the boundaries of the safe operating envelope. After exploring some of these additional plugging mechanisms beyond that currently being considered, the twoway coupling of chemistry and fluid dynamics (i.e., the influence of waste chemistry on fluid dynamics and the influence of fluid dynamics on waste chemistry) will be discussed. This coupling, represented by the interior of Fig. 2.1 (i.e., not on the axes), must be accounted for to reduce the uncertainty of some waste transfer operating envelopes and to reduce waste transfer risks. The coupling of the chemistry and flow models is needed to reduce or eliminate limiting assumptions.

\subsection{PIPELINE PLUGGING MECHANISMS}

Pipeline plugs may form via a variety of mechanisms. Some of the mechanisms that have been observed or postulated for tank waste transfers are shown in Table 3.1. Illustrations of the mechanisms are provided in Figs. 3.1(a)-3.1(f).

These plugging mechanisms are described as follows:

Mechanism \#1: Solids settling (slurries with a static PSD). Much of the waste transfer analysis at Hanford has focused on this mechanism of pipeline plugging. Solids from the waste slurry settle because the flow velocity is insufficient to keep them suspended. The settled solids form a stationary bed that eventually fills the pipe and blocks flow. The critical velocity and pressure drop are calculated based on the slurry's physical and transport properties as well as the pipe dimensions. These critical velocity correlations can also be use in some cases for dynamic PSDs: that is, if the particle dynamics are slow (Damköhler number $\mathrm{Da}<<1)$ or very fast $(\mathrm{Da}>>1)$ relative to the transport times.

\footnotetext{
Mechanism \#2: Slurry flow with dynamic PSDs due to particle agglomeration, fragmentation, precipitation, or chemical reaction. In actual waste transfers, the slurry PSD is frequently dynamic. The shear stress of the pump or of the turbulent flow may break up fragile agglomerated particles. Chemical adjustments, mixing of waste streams, or particle-particle interactions during transport may promote particle agglomeration, resulting in larger particles. Cooling of the slurry in transit or fluctuations in local concentrations may initiate crystallization from the liquid carrier and result in a higher solids volume in the slurry. If the kinetics of these processes are very slow or very fast relative to the transfer residence
} 
Table 3.1. Tank waste plugging mechanisms in pipelines

\begin{tabular}{|c|c|c|c|}
\hline $\begin{array}{l}\text { Plugging } \\
\text { mechanism }\end{array}$ & $\begin{array}{c}\text { Description of } \\
\text { plugging mechanism }\end{array}$ & $\begin{array}{l}\text { Where mechanism has } \\
\text { been observed, suspected, } \\
\text { or could potentially exist }\end{array}$ & Limiting conditions \\
\hline $\begin{array}{l}\text { \#1: Solids settling, } \\
\text { static PSD (see } \\
\text { Fig. 3.1a) }\end{array}$ & $\begin{array}{l}\text { Solids settle on the } \\
\text { bottom of the pipe } \\
\text { from a slurry with a } \\
\text { static PSD }\end{array}$ & $\begin{array}{l}\text { Cross-site transfers of } \\
\text { sludge-water slurry }\end{array}$ & $\begin{array}{l}\text { Flow velocity, solids volume } \\
\text { fraction, solids density, solids } \\
\text { PSD, temperature }\end{array}$ \\
\hline $\begin{array}{l}\text { \#2: Solids settling, } \\
\text { dynamic PSD (see } \\
\text { Fig. 3.1b) }\end{array}$ & $\begin{array}{l}\text { Solids settle on the } \\
\text { bottom of the pipe } \\
\text { from slurry with a } \\
\text { dynamic PSD due to } \\
\text { precipitation, } \\
\text { agglomeration, etc. }\end{array}$ & $\begin{array}{l}\text { Cross-site transfer or } \\
\text { sludge-supernatant slurry } \\
\text { and salt-well pumping (salt } \\
\text { solution) }\end{array}$ & $\begin{array}{l}\text { Flow velocity, solids volume } \\
\text { fraction, solids density, solids } \\
\text { PSD, precipitation rates, } \\
\text { chemical reaction rates, } \\
\text { agglomeration rates, } \\
\text { temperature }\end{array}$ \\
\hline $\begin{array}{l}\# 3 \text { : Surface } \\
\text { deposition and } \\
\text { crystallization, static } \\
\text { and dynamic PSD } \\
\text { (see Fig. 3.1c) }\end{array}$ & $\begin{array}{l}\text { Solids adhere to the } \\
\text { pipe surface or } \\
\text { crystallize on the } \\
\text { surface }\end{array}$ & $\begin{array}{l}\text { Evaporator lines at } \\
\text { Savannah River. Solutions } \\
\text { containing silica and } \\
\text { alumina }\end{array}$ & $\begin{array}{l}\text { Surface deposition rates, } \\
\text { crystallization rates, flow } \\
\text { velocity, temperature }\end{array}$ \\
\hline $\begin{array}{l}\text { \#4: Bulk of slug } \\
\text { plugging }\end{array}$ & $\begin{array}{l}\text { Flow keeps rapidly } \\
\text { forming solids } \\
\text { suspended until entire } \\
\text { cross section is } \\
\text { plugged }\end{array}$ & $\begin{array}{l}\text { Salt solutions containing } \\
\text { phosphate }\end{array}$ & $\begin{array}{l}\text { Flow velocity, flow regime, } \\
\text { metastable state formation } \\
\text { kinetics, temperature }\end{array}$ \\
\hline $\begin{array}{l}\text { \#5: Packed bed in } \\
\text { vertical flow }\end{array}$ & $\begin{array}{l}\text { Packed bed forms at } \\
\text { the base of vertical leg } \\
\text { if flow rate is below } \\
\text { the terminal velocity }\end{array}$ & $\begin{array}{l}\text { Vertical legs leading to } \\
\text { Waste Treatment Plant }\end{array}$ & $\begin{array}{l}\text { Flow velocity, solids volume } \\
\text { fraction, PSD, solids density, } \\
\text { temperature }\end{array}$ \\
\hline $\begin{array}{l}\text { \#6: Depositions at } \\
\text { elbows, constrictions, } \\
\text { etc. }\end{array}$ & $\begin{array}{l}\text { Solids deposit at low- } \\
\text { flow zones }\end{array}$ & $\begin{array}{l}\text { PUREX connectors, } \\
\text { orifices in valve pits }\end{array}$ & $\begin{array}{l}\text { 3-D velocity field, flow } \\
\text { velocity, solids volume } \\
\text { fraction, solids density, solids } \\
\text { PSD, precipitation rates, } \\
\text { chemical reaction rates, } \\
\text { agglomeration rates, } \\
\text { temperature }\end{array}$ \\
\hline
\end{tabular}

time, then the usual methods used for Mechanism \#1 can be applied with a suitable adjustment for the slurry properties in the latter case. However, if the kinetics of the process are on the same order of magnitude as the transfer residence time ( $\mathrm{Da} \approx 1$ ), the PSD dynamics along the flow path may need to be included, depending on the objectives of the analysis. Analysis of this mechanism requires that models account for both flow phenomena and particle dynamics. This mechanism could apply to salt-well pumping or some waste slurry transfers.

Mechanism \#3: Uniform deposition of solids on pipe wall and other surfaces. If solids attach to the pipe wall, a solid layer could build up that would eventually choke off flow. Some components in the waste may adhere to the wall, or the wall could serve as a nucleation site for crystallization. The roughness of the wall and material of construction would influence which compounds adhere. Uniform growth of a deposition layer is more likely to occur in the laminar flow regime but could also occur in turbulent flow. Analysis of this mechanism requires that models account for both flow phenomena and 
(a)
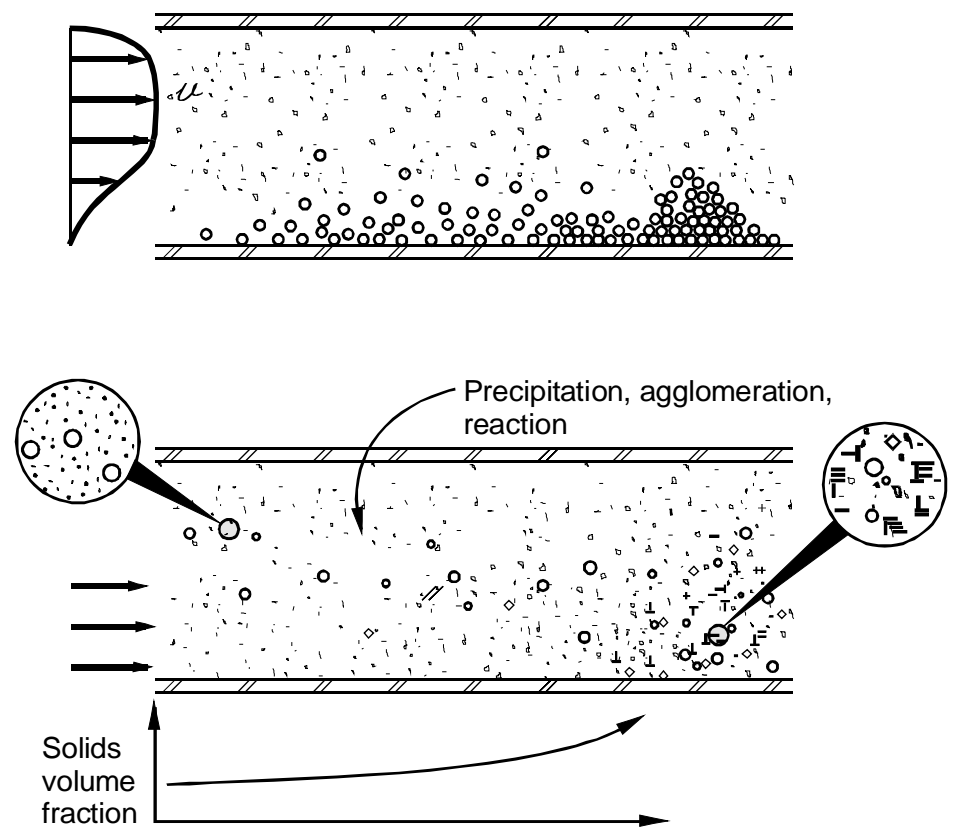

(c)

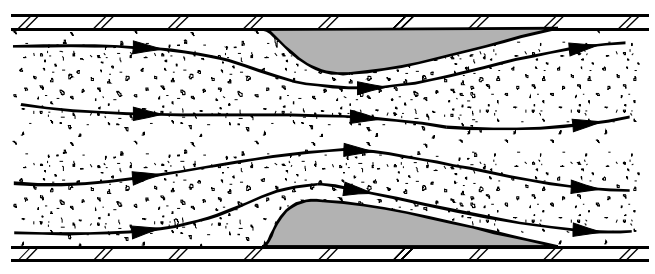

(d)

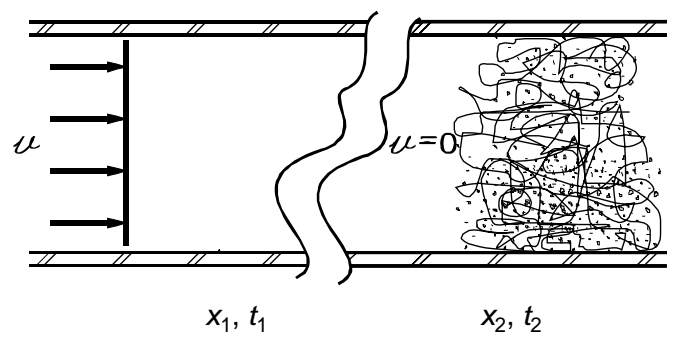

(e)
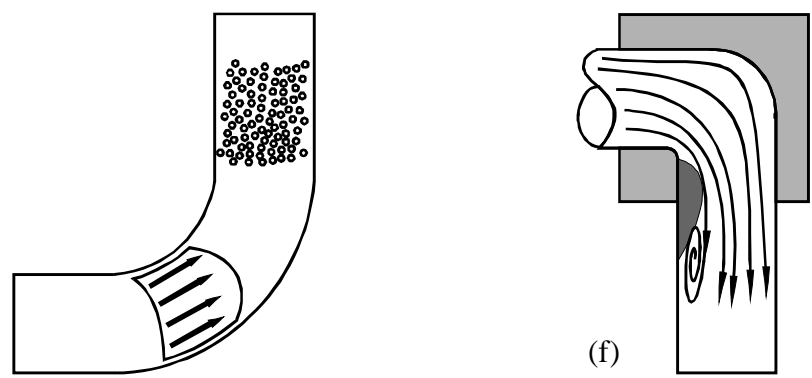

Fig. 3.1. Waste pipeline plugging mechanisms. (a) Solids settling (static particle-size distribution), (b) solids settling (dynamic particle-size distribution), (c) surface deposition, (d) bulk or slug plugging, (e) packed bed formation in vertical leg, and (f) deposition at flow "dead zones" in elbows. 
particle dynamics. This mechanism could apply to salt or sludge transfers. Deposits that appear to have been formed by this mechanism have been observed in evaporator piping at Savannah River. See Hu et al. (2001) for results of recent tests aimed at understanding scale formation in the $2 \mathrm{H}$ evaporator.

Mechanism \#4: Bulk "instantaneous" plugging. Rapid reactions such as that associated with the change in the waters of hydration of phosphates and formation of metastable colloidal phases and gels could result in maintenance of pumpable fluid slurry until a local critical condition is reached, resulting in a very rapid transition. The result is a nearly instantaneous dramatic change in the local property, such as the viscosity, particle volume fraction, PSD, or morphology. This mechanism could be modeled by relatively simple treatment of the fluid velocity profiles but would require a good description of the chemical kinetics and other phenomena that control the bulk plug formation. See Hunt et al. (2000) for examples of both sludge and salt solutions that could be susceptible to this bulk plugging behavior.

Mechanism \#5: Upward flow in vertical pipes. In vertical pipe runs, the liquid velocity must exceed the terminal velocity of the largest particle in the slurry. A bed of solids will form at the base of the vertical leg if the velocity is too low. This mechanism of plugging can occur with salt and sludge transfers.

Mechanism \#6: Solids deposition at elbows, constrictions, and other flow dead zones. Solids may deposit at a sharp elbow due to the impingement and sticking of solid particles onto the wall, or solids may accumulate in dead zones in the flow system. Since this involves three-dimensional turbulent flow, predicting this disposition would require the most sophisticated fluid dynamics treatment.

\subsection{THE COUPLING OF FLUID DYNAMICS AND CHEMISTRY}

To calculate the critical velocity and the pressure drop for slurries containing narrowly sized, static spherical particles, the solids volume fraction, particle diameter, particle density, liquid density, and viscosity of the liquid carrier are required. If the solids are polydispersed and nonspherical, then the PSD and particle-shape distribution must also be known. The solids volume fraction, mean particle size, PSD, and particle shape also influence the viscosity of the homogeneous slurry (e.g., Macosko 1994) and the particle hindered settling velocity (e.g., Shor and Watson 1990). The dependence of viscosity and settling velocity on solids volume fraction is strongly nonlinear.

PSD and particle shape directly and indirectly affect the velocity distribution and the settling of particles in the slurry. The baseline correlation presented in Sect. 2.1 does not account for PSD or particle shape and assumes that the mean particle diameter does not change during a transfer.

Fluid dynamic forces and changes in the chemical environment, temperature, and pressure can all result in dramatic changes in the slurry particle properties in transit, which in turn result, in dramatic changes in the flow behavior. Some of the chemical and mechanical phenomena that may be encountered are summarized below.

Breakup of solids due to shear forces. If the particles are agglomerates formed from smaller particles, then the shear forces encountered in pumping or in flow may be sufficient to break the agglomerates into finer individual particles. This has been observed in tests with tank sludge subject to shear (Herting 2000c).

Agglomeration of particles due to changes in the chemical environment, particle-particle interactions, or shear. The flocculation of particles by adjusting $\mathrm{pH}$ is a common industrial process to aid solid-liquid separation (e.g., Chin et al. 1998). In considering industrial crystallizers, understanding the influence of PSD, shear, solids volume fraction, and chemistry are essential for control and 
optimization. Melis et al. (1999) and Serra and Casamitjana (1998) describe the effect of shear and other factors on agglomeration. Tests are being conducted by AEA Technology plc for the TFA to measure agglomeration and breakup rates for simulated tank waste sludge.

Precipitation and chemical reaction. If the waste being transported is not in chemical equilibrium or if the waste temperature drops in transit, then additional solids may form. As a result, the solids volume fraction and the viscosity increase. The TFA has been conducting tests with simulated wastes to characterize the solids formed and to measure the viscosity under possible operating conditions (Hunt et al. 2000). ESP is used to compare experimental results with chemical equilibrium calculations; however, the rapid formation of metastable gels that has been observed in narrow temperature ranges (Hunt et al. 2000) is not predicted by ESP.

Ordering and clustering of solids due to the fluid-particle flow field. The ordering of charged colloids to form metastable phases has received much recent attention (see Arora and Tata 1996). However, particle order can also result from purely fluid-mechanics forces. The particular metastable structure that forms depends on the shape and relative sizes of the particles, the solids volume fraction, and the flow regime. For example, Qi (1999) describes how cylindrical particles form "T-clusters" during sedimentation. These constitute perhaps a precursor of the mats of needle particles that have been observed in plugs of phosphate waste tank pipelines. Clustering is not limited to asymmetrically shaped particles. Formation of transient ordered clusters of particles has also been observed for the flow of spherical particles.

Nonequilibrium of flowing systems. On a more fundamental level, one needs to know what happens when a suspension of colloidal particles in thermodynamic equilibrium is perturbed by changing its temperature or by imposing flow. Sometimes the equilibrium parameters no longer apply. The recent work of Jou et al. (2000) and Cates and Evans (1999) provides some interesting examples and theory of nonequilibrium dynamics and flow of "fragile" matter.

Chemistry affects flow and flow affects chemistry (see Fig. 3.2). When coupling can be ignored and when it must be considered is a significant issue. To address some of these questions, experimental work with simulated sludge wastes and salt wastes are being conducted by the TFA at FIU and MSU, respectively. But to interpret and apply these data, models with capabilities beyond those currently in use are required. Referring to Fig. 2.1, models that have enough chemistry and fluid dynamics to describe essential features of waste flow but are simple enough to be developed and deployed to current site problems are needed. 


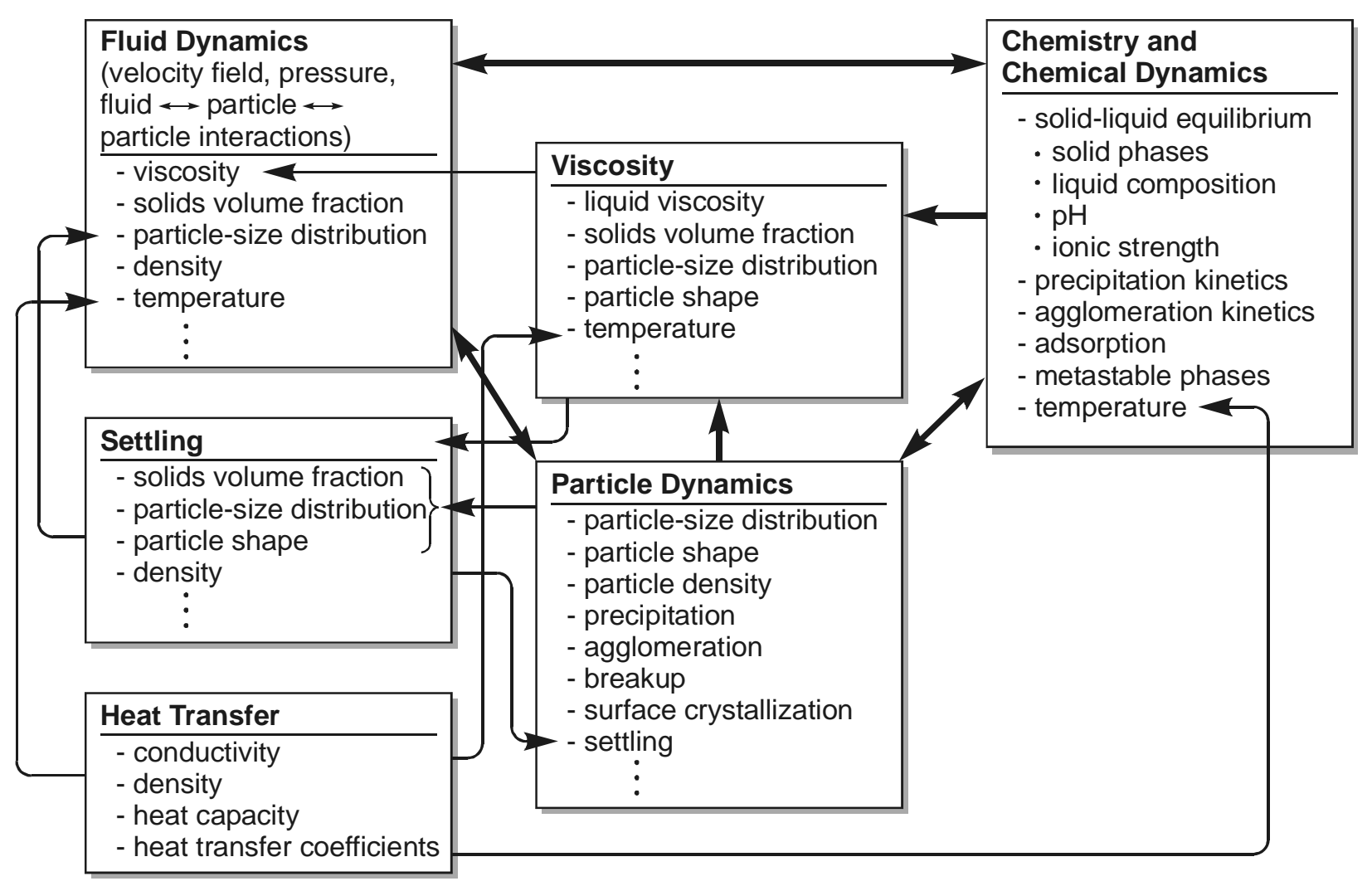

Fig. 3.2. Coupling of fluid dynamics and chemistry in waste transport. 


\section{PROSPECTS FOR IMPROVED TRANSPORT ANALYSIS TOOLS AND RISK REDUCTION}

\subsection{ASSESSMENT OF EXISTING TOOLS AND PROCEDURES}

Waste transfer criteria should account for all the relevant factors (be complete), should give accurate predictions of the waste transfer stability, and should also be practical in terms of implementation on site. The criteria are complete if all the principal factors that define the "real" boundary for stable operations can be identified and quantified. By operating within this "real" envelope, the risk of pipeline plugging and other operating problems is eliminated. If we know accurate locations for these boundaries and have good controls, we can operate closer to the edge to increase throughput, decrease water addition, or meet some other objective. (Actually, if this could be considered a linear programming problem, we would want to operate at the vertex of constraints rather than the edge to optimize operations, the particular vertex depending upon the optimization objective.) But developing the data, predictive tools, and understanding needed to locate the operating boundaries completely and accurately takes time and money. In addition, because of the complexity of the phenomena, the predictive tools needed to define the operating conditions will likely be more detailed than those that are eventually deployed in the field. Nevertheless, the ultimate product of these efforts, whether they be data packages, operating procedures, guidelines, rules of thumb, or predictive tools, must be practical for implementation in the field.

Several studies of strategies for defining waste transfer criteria have been done. Shekarriz et al. (1997), building on the method proposed by Hudson (1996), recommended an iterative approach that involved (1) predictive analysis, (2) validation using laboratory data and field experiments, and (3) control analysis. They proposed to calculate the solids volume fraction and composition prior to transfer using an equilibrium chemical code and to calculate the critical velocity and pressure drop using the correlations of Oroskar and Turian (1980) and Wasp et al. (1979). The procedure included identification of known problematic waste constituents.

The existing tools and procedures do not directly address the various plug formation mechanisms or the waste dynamics during transport discussed in the previous section. Limiting the chemistry analysis to equilibrium calculations has several consequences. On the one hand, the predictions may be overly conservative. If a stable species not initially present is predicted from the initial waste composition and planned transfer conditions but the rate of formation is very slow, then the amount of water or other carrier liquid will be predicted to be higher than actually required. Of course, we would also need to assess the consequences of process upsets and interruptions as well. On the other hand, the equilibrium chemistry prediction may be too optimistic. The equilibrium calculations yield the final products but provide no information about the concentration of any intermediates formed in transit. The concentration and the in-flow behavior of intermediates cannot necessarily be interpolated from the initial and final equilibrium states. Nor does the equilibrium calculation predict the formation of gels or metastable phases for which formation is influenced by chemical-flow coupling. The critical velocity slurry flow correlations provide no information about the spatial and dynamic behavior as discussed before.

Some of the current and proposed initiatives to address some of these issues are discussed in the following section.

\subsection{CAPABILITIES NEEDED FOR WASTE TRANSFER EVALUATIONS}

There are four possible paths to a more complete and accurate description of waste transport behavior and stability as shown in Fig. 4.1. Path 1 concentrates on describing the fluid dynamics, adding chemical and 


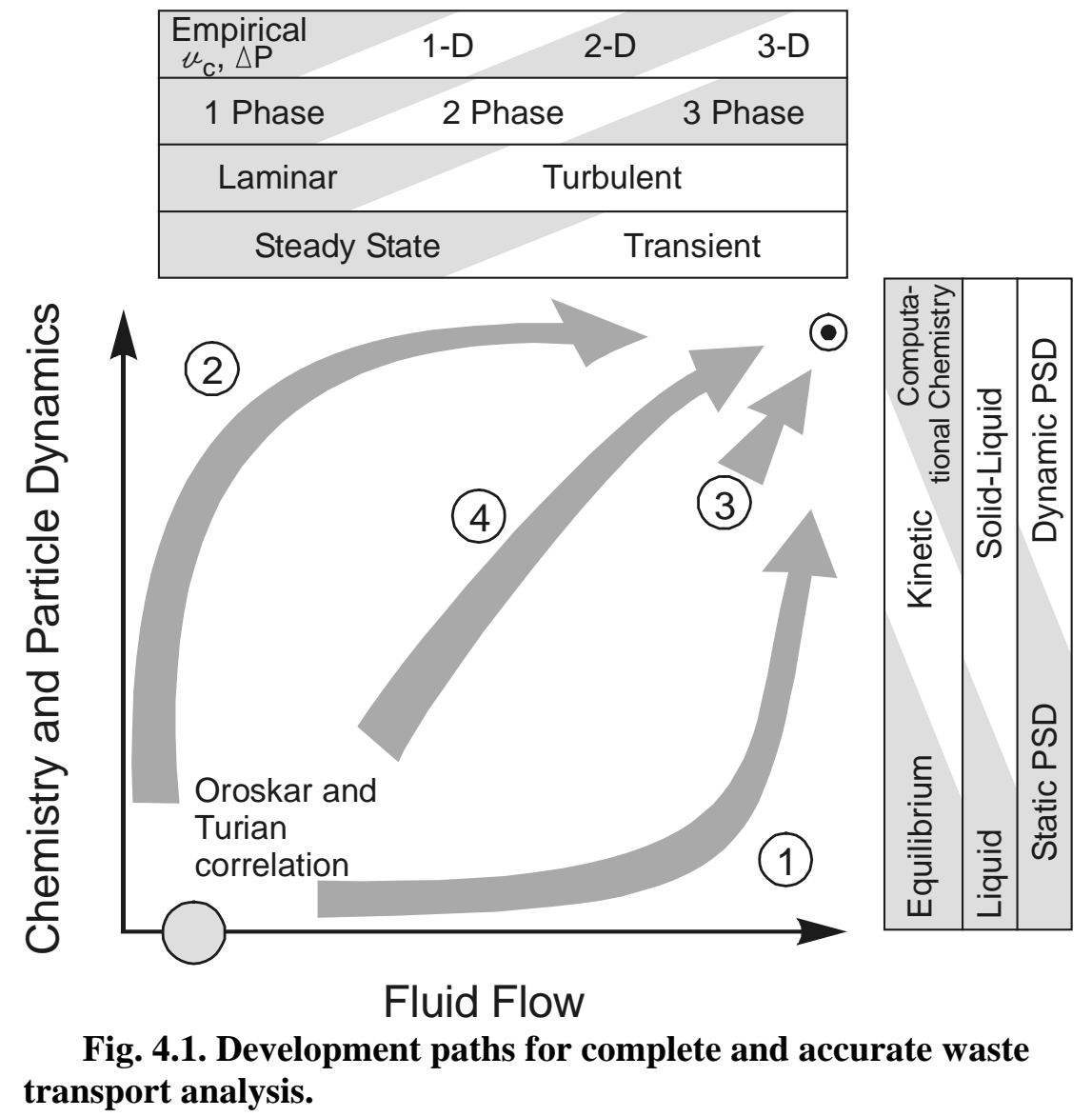

particle dynamics along the way. Path 2 concentrates on the chemistry, equilibrium and kinetics and then adds the coupling with flow. Path 3 attempts to account for all aspects at once, a very complex and difficult problem. Path 4 includes key features of both the flow and chemistry, moving incrementally toward a more complete and accurate description of waste transport behavior. This path is proposed here to balance completeness, accuracy, and near-term application. This approach will put practical tools in the hands of site designers and analysts as soon as possible.

Efforts to extend and validate current models being used to evaluate waste transfers are necessary and worthwhile. However, these efforts alone are not sufficient and will neither provide the tools needed to reduce most uncertainties nor address transfer scenarios beyond the capabilities of current methods of analysis. Furthermore, new modeling capabilities provide the tools for many additional beneficial applications as outlined in this section. Table 4.1 outlines the capabilities needed in future tools, their potential application, and the benefits of their use. The choice of predictive tools to evaluate a waste transfer depends on both the purpose of the evaluation and on the plugging mechanisms most likely to be relevant for that transfer.

Progress is being made in the extending and validating the empirical correlations for slurry flow with a static PSD (Mechanism \#1). TFA work is ongoing at FIU to obtain data for slurries with solids having a PSD similar to that of the Hanford wastes. These data are then regressed by researchers at FIU and PNNL to adjust correlation parameters. Under another TFA task at ORNL in FY 2002, viscosity and hindered 
Table 4.1. Present status and prospects for tools to analyze tank waste pipeline plugging

\begin{tabular}{|c|c|c|c|}
\hline Plugging mechanism & $\begin{array}{c}\text { Current predictive } \\
\text { tools }\end{array}$ & $\begin{array}{l}\text { Predictive tools, data, and } \\
\text { data models needed }\end{array}$ & $\begin{array}{c}\text { Benefits of models with } \\
\text { enhanced capabilities and } \\
\text { new applications }\end{array}$ \\
\hline $\begin{array}{l}\text { \#1: Solids settling, } \\
\text { static PSD }\end{array}$ & $\begin{array}{l}\text { - Critical velocity } \\
\text { empirical } \\
\text { correlation, Oroskar } \\
\text { and Turian (1980) } \\
\text { - Pressure loss, } \\
\text { empirical } \\
\text { correlation Wasp } \\
\text { (1979) } \\
\text { - ESP to calculate } \\
\text { initial composition } \\
\text { and solid content } \\
\text { for salt solutions }\end{array}$ & $\begin{array}{l}\text { - PSD and particle shape- } \\
\text { effects on properties and } \\
\text { flow } \\
\text { - Viscosity and hindered } \\
\text { settling models = f(solids } \\
\text { volume fraction, PSD, } \\
\text { particle shape) } \\
\text { - Integrate heat transfer } \\
\text { analysis }\end{array}$ & $\begin{array}{l}\text { - More accurate critical } \\
\text { velocity and pressure drop } \\
\text { - Potentially higher solids } \\
\text { content, less diluent, less } \\
\text { carrier liquid }\end{array}$ \\
\hline $\begin{array}{l}\text { \#2: Solids settling } \\
\text { and deposition, } \\
\text { dynamic PSD } \\
\text { (precipitation, } \\
\text { agglomeration, } \\
\text { breakup) }\end{array}$ & & $\begin{array}{l}\text { - Agglomeration and breakup } \\
\text { data and models } \\
\text { - Precipitation kinetics data } \\
\text { and models } \\
\text { - Slurry/salt flow model: 1-D } \\
\text { or 2-D, PSD = f(composi- } \\
\text { tion, precipitation, } \\
\text { agglomeration, breakup, } \\
\text { flow, T) } \\
\text { Bed depth }=\mathrm{f}(\mathrm{x}, \mathrm{t}) \\
\text { Surface interaction kinetics } \\
\text { - Viscosity and hindered } \\
\text { settling models = } \\
\text { f(composition, solids } \\
\text { volume fraction, PSD, } \\
\text { particle shape, T) }\end{array}$ & $\begin{array}{l}\text { - Risk reduction by more } \\
\text { accurate operating } \\
\text { boundaries } \\
\text { - Avoid unstable mixtures due } \\
\text { to flow-chemistry coupling } \\
\text { - Provide local pressure, } \\
\text { temperature, concentrations, } \\
\text { and bed depth } \\
\text { - Less safety margin required } \\
\text { - Less carrier liquid } \\
\text { - Provides tool to evaluate } \\
\text { unplugging methods } \\
\text { - Minimize dilution water for } \\
\text { salt transfers } \\
\text { - Reduce downtime required } \\
\text { to unplug salt-well pipelines, } \\
\text { increase availability } \\
\text { - Optimize operations } \\
\text { - Analysis of the dynamics of } \\
\text { process upsets such as loss } \\
\text { of pumping }\end{array}$ \\
\hline $\begin{array}{l}\text { \#3: Surface } \\
\text { deposition }\end{array}$ & & $\begin{array}{l}\text { - 1-D or 2-D slurry/salt } \\
\text { model with deposition layer } \\
=\mathrm{f}(\mathrm{x}, \mathrm{t}) \\
\text { - Surface interaction kinetics }\end{array}$ & $\begin{array}{l}\text { - Predict time to plug and plug } \\
\text { location } \\
\text { - Provides tool to evaluate } \\
\text { prevention and unplugging } \\
\text { methods }\end{array}$ \\
\hline $\begin{array}{l}\text { \#4: Bulk or slug } \\
\text { plugging }\end{array}$ & & $\begin{array}{l}\text { - } 1 \text {-D slurry/salt flow model } \\
\text { reaction }+ \text { precipitation }+ \\
\text { agglomeration }=f(x, t)\end{array}$ & $\begin{array}{l}\text { - Permits identification of } \\
\text { unstable operating conditions }\end{array}$ \\
\hline $\begin{array}{l}\text { \#5: Packed bed in } \\
\text { vertical flow }\end{array}$ & & $\begin{array}{l}\text { - Terminal velocity correla- } \\
\text { tion for a concentrated } \\
\text { slurry = f(PSD, shape })\end{array}$ & $\begin{array}{l}\text { - Add to standard evaluation } \\
\text { to avoid this type of } \\
\text { plugging }\end{array}$ \\
\hline $\begin{array}{l}\text { \#6: Deposition at } \\
\text { elbows, constrictions, } \\
\text { etc. }\end{array}$ & & $\begin{array}{l}\text { - Tests to ID key parameters } \\
\text { CFD with reaction }+ \\
\text { deposition }+ \text { precipitation }+ \\
\text { agglomeration } \\
\end{array}$ & $\begin{array}{l}\text { - Evaluate plugging potential } \\
\text { for transfers } \\
\text { - Evaluate connector designs }\end{array}$ \\
\hline
\end{tabular}


settling models that account for solids volume fraction, PSD, and particle shape are being reviewed and adapted for applications with these correlations. Measurement of the viscosity of simulated wastes is an ongoing effort at Oak Ridge National Laboratory (ORNL) to provide needed data.

Work to develop the data and data models and to describe the dynamic PSD (Mechanism \#2, Row 2 of Table 4.1) is also under way. AEA Technology plc is measuring kinetic constants for precipitation and agglomeration (Henshaw 1999; Francis et al. 2000). In FY 2002, the author of this report will be developing models to add some of the capabilities listed in this table under "Predictive Tools, Data, and Data Models Needed" for dynamic PDS (Mechanism \#2), and "bulk" plugging (Mechanism \#4). In addition a review of kinetic data and data models will be carried out.

The benefits of and potential new applications for the products of these efforts are listed in the final column of Table 4.1. In addition to the six listed, each plugging mechanism may result in unique pressure and flow "signatures." If the appropriate models are available, these signatures can be interpreted to help identify the plugging mechanism or to play a role in the real-time control of the process.

Additional uses are as follows: understanding the plug formation mechanism will help in the formulation and evaluation of unplugging methods, process control design and operation, and process optimization.

TFA is conducting experimental studies at FIU to obtain data for simulated waste with a PSD representative of that of the Hanford wastes. In addition "numerical experiments" using a CFD code were conducted in 2000 and 2001 at MSU to compute critical velocities, allowing a comparison of these computed velocities with those predicted by Oroskar and Turian (1980). In addition, RPP-sponsored studies are ongoing at Hanford to evaluate the uncertainty in tank waste particle size data.

Work is ongoing to measure some of these data, either by characterization of actual wastes or by measurements of simulated tank waste. TFA work to measure particle density, PSD, particle shape, and viscosity is ongoing at AEA Technology plc, FIU, MSU, and ORNL. 


\section{CONCLUSIONS AND RECOMMENDATIONS}

This report identifies the fluid dynamics and chemical modeling capabilities needed to reduce the risk of pipeline plugging during tank waste transfers at Hanford, evaluates some of the modeling tools currently in use for waste transfer analysis relative to these needs, and recommends actions to address capability gaps.

Six distinct and credible waste pipeline plugging mechanisms have been identified. However, the tools currently being used by the site for design and waste transfer evaluations can directly address only one of these-development of a blockage due to solids settling from a slurry with a static PSD. The static PSD plugging mechanism is relevant for many sludge-water transfers, but models capable of assessing the other five plugging mechanisms are needed.

Current evaluations focus on (1) empirical critical velocity fluid mechanics correlations and (2) separate equilibrium chemistry calculations to estimate the initial waste compositions and solids volume fraction. Precipitation, gelation, other chemical reactions, particle agglomeration, particle breakup, and other dynamic processes occur in some waste transfers. Waste-surface interactions can also be important. In addition, waste chemistry and flow are coupled-chemistry affects the flow, and flow affects the chemistry. A model capable of describing these dynamic and coupled processes is essential for predicting four of the six plugging mechanisms.

Extension and validation of the current models used to evaluate waste transfers such as the empirical correlation of Oroskar and Turian and the ESP equilibrium chemistry code are necessary to improve the accuracy for slurry-water transfers and to provide the initial conditions for waste transfers. RPP and TFA are working to validate and improve these tools for analysis of the static PSD case.

Predictive tools developed for waste transfer analysis must ultimately be practical for implementation in the field. Application of a three-dimensional CFD model has been explored by TFA as an approach to model some dynamic effects, but it was concluded that following the CFD-based path should be deferred until it becomes easier to implement, faster computers become available to the design and analysis staff, and theoretical difficulties associated with bed mechanics are overcome. CFD will eventually play an increasing role in waste transport analysis, and it can now be productively applied to some specialized analyses.

Current waste transfer criteria were developed without considering all plugging mechanisms, chemical dynamics, or flow-chemistry coupling. Performing tests without the models needed to understand and apply the results will be insufficient to reduce the risk of pipeline plugging. The tank wastes are a complicated chemical system. The important complexities must be understood in order to identify the phenomena involved and to provide a description of these in practical and accurate tools.

Practical models with additional capabilities are needed to address all credible plugging mechanisms. In FY 2002, the TFA is funding a limited initiative at ORNL to address some of these needs. Predictive models that account for chemical-flow coupling and PSD dynamics along the flow route are being developed to provide the capabilities needed to evaluate waste transfers for most of the plugging mechanisms that are not presently being addressed. The resulting models will also be applicable to process control, real-time detection and prevention of plugging, diagnosis of plugging events, evaluation of unplugging methods, and process optimization.

Transport model development work in FY 2002 will focus on (1) support of salt solution transport projects and operations (e.g., the S-112 project and salt-well pumping) and (2) improvements to the 
hindered settling correlation to account for settling of polydispersed solids and particle shape. In early FY 2002, a literature review of alternative potential models will be published. Model requirements and a model development plan will then be developed and reported in collaboration with Hanford operations and project users. To make the models useful as early as possible in the process, the capabilities of the models will be developed and introduced incrementally. One will be a laminar flow model with dynamic PSD (mechanism 2) to describe salt solution behavior in pipelines. This model will be applied to analysis of transfers from trickle-bed saltcake dissolution and salt-well pumping operations. A second model will be a turbulent flow model with dynamic PSD to describe sludge-slurry transfers and salt-solution transfers susceptible to bulk plugging. New kinetic data will be required for these models. The specific processes and components to be included will be selected based on an analysis of the models and the pipeline conditions to be addressed. A "bulk-thickening" model will be needed for very rapid transitions to metastable gel states. Surface interaction and metastable processes will be added to the model later (see mechanisms 3 and 4). In general, the simplest possible treatment of the velocity profile will be used. The ability to describe transient behavior will be included, at least to the extent of that changes in the PSD are described. When the dynamics are relatively slow, the problem can be analyzed by making quasi-steadystate assumptions.

RPP and TFA are developing some of the data and data models to support these evaluations and models. This work includes collecting data on precipitation and dissolution kinetics, slurry flow studies, salt-well pumping flow studies, measurements of agglomeration and breakup kinetics, viscosity data measurements, and improvements to viscosity and hindered settling models. However, more remains to be done to develop data and models, validate the models, and reduce the calculations to practical tools that can be applied in the field.

TFA is conducting waste flow tests in pipeline mockups at FIU and MSU to provide data related to slurry transport, salt-well pumping, and saltcake dissolution and transfer. These studies are essential for providing the data to validate predictive models and for gaining insight into the chemical behavior of waste in flow.

The development of simple decision criteria or a "stability map" to identify which waste chemistries and transfer conditions require detailed analysis might be useful as a rule of thumb. This map would be different from what is currently available in that it would include both fluid dynamics and chemical dynamics parameters. However, such a map should only be considered a guide. Actual transfers should be analyzed with the best tools available.

For those waste chemistries and transfer conditions for which detailed analysis is indicated, waste transfers should be evaluated using the appropriate predictive tools, results should be validated with tests using simulated and real wastes, and additional data and model development needs should be identified.

Collecting the right data is essential for application of the predictive models and for minimizing the cost of research, development and waste characterization. The models should be used to help specify what types of data are required. It is likely that additional kinetic data will be needed.

Predictive models should be applied to additional areas such as real-time process control and process optimization. 


\section{REFERENCES}

Arora, A. K., and B. V. R. Tata (eds.). 1996. Ordering and Phase Transitions in Charged Colloids, VCH Publishers, New York.

Cates, M. E. and M. R. Evans (eds.). 1999. Soft and Fragile Matter: Nonequilibrium Dynamics, Metastability and Flow, Institute of Physics Publishing, Philadelphia.

Chin, C. J., S. Yiacoumi, and C. Tsouris. 1998. "Shear-Induced Flocculation of Colloidal Particles in Stirred Tanks," Journal of Colloid and Interface Science 206, 532-45.

Estey, S. D., and T. A. Hu. 1998. Flow Velocity Analysis for Avoidance of Solids Deposition During Transport of Hanford Tank Waste Slurries, HNF-2728, Lockheed Martin Hanford Corporation, Richland, Washington (October).

Francis, A., J. Henshaw, M. Manning, N. Pilkington, and C. Kemp. 2000. Progress Report on Precipitation Studies of Tank Simulant Mixtures (AN-103, SRS), AEAT/R/NT/0285, AEA Technology, Oxfordshire, U.K. (November).

Garfield, J. S., R. A. Kirkbride, T. M. Hohl, and W. J. Stokes. 2000. Single-Shell Tank Retrieval Sequence: Fiscal Year 2000 Update, RPP-7087, CH2MHILL Hanford Group, Inc., Richland, Washington (September).

Gillies, R. G., and C. A. Shook. 1991. “A Deposition Velocity Correlation for Water Slurries," Canadian Journal of Chemical Engineering 69, 1225-27.

Henshaw, J. 1999. Summary of Precipitation Studies of Phosphate, Fluoride and Sulphate Solutions in Tank Wastes, AEAT-6256, AEA Technology, Oxfordshire, U.K. (November).

Herting, D. L., D. W. Edmonson, J. R. Smith, T. A. Hill, and C. H. Delegard. 1999. Saltcake Dissolution FY1999 Status Report, HNF-5193, Fluor Daniel Hanford, Inc., Richland, Washington (September).

Herting, D. L. 2000a. Results of Dilution Studies with Waste from Tank 241-AN-103, HNF-7153, Fluor Hanford, Richland, Washington (September).

Herting, D. L. 2000b. Saltcake Dissolution FY 2000 Status Report, HNF-7031, Fluor Hanford, Richland, Washington (September).

Herting, D. L. 2000c. Results of Shear Studies with 241-AZ-102 Sludge, HNF-6585, Fluor Hanford, Richland, Washington (July).

Hu, M. Z., D. W. DePaoli, and D. T. Bostick. 2001. Dynamic Particle Growth Testing: Phase I Studies, ORNL/TM-2001/100, Oak Ridge National Laboratory, Oak Ridge, Tenn (June).

Hudson, J. D. 1996. Defining Waste Acceptance Criteria for the Hanford Replacement Cross-Site Transfer System, PNNL-11146, Pacific Northwest National Laboratory, Richland, Washington (April).

Hunt, R. D., T. A. Dillow, J. R. Parrott, Jr., J. C. Schryver, C. F. Weber, and T. D. Welch. 2000. Waste Preparation and Transport Chemistry: Results of the FY 2000 Studies, ORNL/TM-2000/298, Oak Ridge National Laboratory, Oak Ridge, Tenn. 
Jewett, J. R., and L. Jensen. 2000. Assessment of Available Particle Size Data to Support an Analysis of the Waste Feed Delivery System Transfer System, RPP-6247, CH2MHILL Hanford Group, Inc., Richland, Washington (August).

Jou, D., J. C. Vázquez, and M. Criado-Sancho. 2000. Thermodynamics of Fluids Under Flow, Springer, New York.

Julyk, L. J., J. C. Oten, and W. L. Willis. 2000. Waste Feed Delivery Transfer System Analysis, RPP5346, CH2MHILL Hanford Group, Inc., Richland, Washington (May).

Kuipers, J. A. M., and W. P. M. van Swaaij. 1998. "Computational Fluid Dynamics Applied to Chemical Reaction Engineering," pp. 227-319 in Advances in Chemical Engineering, Vol. 24.

Levenspiel, O. 1962. Chemical Reaction Engineering, John Wiley \& Sons, New York.

Liddell, K. C., and D. F. Burnett. 2000. Critical Transport Velocity: A Review of Correlations and Models, RPP-7185 Rev. 0, CH2MHILL Hanford Group, Richland, Washington (October).

Macosko, C. W. 1994. Rheology: Principles, Measurements, and Applications, VCH, New York.

Maude, A. D., and R. L. Whitmore. 1958. "Hindered Settling,” British Journal of Applied Physics 9, 477-482.

Melis, S., M. Verduyn, G. Storti, and M. Morbidelli. 1999. "Effect of Fluid Motion on the Aggregation of Small Particles Subject to Interaction Forces," AIChE Journal 45, 1383-1393.

Onishi, Y., D. S. Trent, T. E. Michener, J. E. Van Beek, and C. A. Rieck. 1999. "Simulation of Radioactive Tank Waste Mixing with Chemical Reactions," in Proceedings of 3rd ASME/JSME Joint Fluids Engineering Conference, FEDSM99-7786, San Francisco (July).

Orme, R. M. 1999. Waste Feed Delivery Technical Basis, Volume II, Waste Feed Delivery Flowsheet for 241-AN-105, (HNF-1939, Rev. Ob), HNF-1939-Vol. II, Numatec Hanford Corp., Richland, Washington (May).

Oroskar, A. R., and R. M. Turian. 1980. "The Critical Velocity in Pipeline Flow of Slurries," AIChE Journal 26(4), 550-58.

Qi, D. 1999. "Lattice Boltzmann Simulations of Sedimentation of Cylindrical Particles in a ThreeDimensional Space," Advanced Technologies for Fluid-Particle Systems, AIChE Symposium Series, No. 321, Vol. 95.

Richardson, J. F., and W. N. Zaki. 1954. "The Sedimentation of a Suspension of Uniform Spheres Under Conditions of Viscous Flow," Chemical Engineering Science 3, 65-73.

Serra, T., and X. Casamitjana. 1998. "Effect of the Shear and Volume Fraction on the Aggregation and Breakup of Particles," AIChE Journal 44, 1724-30.

Shekarriz, A., Y. Onishi, P. A. Smith, M. Sterner, C. R. Rector, and J. Virden. 1997. Cross-Site Transfer System at Hanford: Long Term Strategy for Waste Acceptance, PNNL-11497, Pacific Northwest National Laboratory, Richland, Washington (February). 
Shor, J. T., and J. S. Watson. 1990. "The Sedimentation of Bimodal Distributions of Unflocculated Microspheres," Separation Science and Technology 25, 2157-70.

Toghiani, B., and J. S. Lindner. 2001. DIAL/MSU Saltcake Dissolution: Fiscal Year 2000 Status Report, TR 00-1, Tanks Focus Area, Mississippi State University, Starkville, Miss.

Toghiani, B., J. S. Lindner, C. F. Weber, and R. D. Hunt. 2000. Modeling of Sulfate Double-Salt in Nuclear Wastes, ORNL/TM-2000/300.

Travis, J. R. 1985. Two-Field and Drift-Flux Models with Application to Nuclear Reactor Safety, LA-UR85-3689, Los Alamos National Laboratory, Los Alamos, New Mexico (November).

Wasp, E. J., J. P. Kenny, and R. L. Gandhi. 1979. Solid-Liquid Flow Slurry Pipeline Transportation, Gulf Publishing Company, Houston. 



\section{BIBLIOGRAPHY}

\section{TANK WASTE TRANSPORT}

Carleson, T. E., D. C. Brown, and R. E. Hart, Evaluation of the Transport and Resuspension of a Simulated Nuclear Waste Slurry, PNL-6302, Pacific Northwest Laboratory, Richland, Washington (September 1987).

\section{SLURRY TRANSPORT}

12th International Conference on Slurry Handling and Pipeline Transport: Hydrotransport 12, ed. C. A. Shook, Mechanical Engineering Publications, Limited, London, 1993.

13th International Conference on Slurry Handling and Pipeline Transport: Hydrotransport 13, ed. J. F. Richardson, Mechanical Engineering Publications, Limited, London, 1996.

Binder, J. L., and T. J. Hanraty, "Use of Lagrangian Statistics to Describe Slurry Transport," AIChE Journal 39, 1581-91 (1993).

Cheremisinoff, N. P., Encyclopedia of Fluid Mechanics, Vol. 5, Slurry Flow Technology, Gulf Publishing Company, Houston, Texas, 1986.

Clift, R., J. R. Grace, and M. E. Weber, Bubbles, Drops, and Particles, Academic Press, New York, 1978.

Drew, D. A., "Continuum Modeling of Two-Phase Flows," in Theories of Dispersed Multiphase Flow, ed. R. Meyer, 1983.

Gross, R. J., and M. R. Baer, A Study of Numerical Solution Methods for Two-Phase Flows, SND841633, Sandia National Laboratory, Albuquerque, New Mexico (April 1986).

Heywood, N. I., "Stop Your Slurries from Stirring up Trouble," Chemical Engineering Progress, pp. 21-41 (1999).

Hoffmann, A. C., and J. Kevelaml, "Model for Interparticle Surface Separation in Concentrated Monoand Polydisperse Suspensions," AIChE Journal 45, 285-90 (1999).

Johnson, G., G. M. Massoudi, and K. R. Rajagopal, A Review of Interaction Mechanisms in Fluid-Solid Flows,” DOE/PETC/TR-90/9, U.S. Department of Energy, Pittsburgh Energy Technology Center, Pittsburgh, Pennsylvania (1990).

Nunziato, J. W. A., "Multiphase Mixture Theory of Fluid-Particle Flows," in Theories of Dispersed Multiphase Flow, ed. R. Meyer, 1983.

Pumping Sludge and Slurry, Power Industries Division of the Institution of Mechanical Engineers, Mechanical Engineering Publications Limited, London, 1998.

Wallis, G. B., One-Dimensional Two-Phase Flow, McGraw-Hill Book Company, New York, 1969. 


\section{VISCOSITY}

Kapur, P. C., P. J. Scales, D. V. Boger, and T. W. Healy, "Yield Stress of Suspensions Loaded with Size Distributed Particles," AIChE Journal 43, 1171-79 (1997).

Kasper, G., T. Niida, and M. Yang, "Measurement of Viscous Drag on Cyclinders and Chains of Spheres," Journal of the Aerosol Science 16(4), 535-56 (1985).

Kim, H. J., et al., Advanced Study in Solid Transport: Rheological Behavior of Dense Suspension, DOE/PC/88949-T8 (October 1990).

Lionberger, R. A., "Microscopic Theories of the Rheology of Stable Colloidal Dispersions," in Advances in Chemical Physics, Vol. 111 (2000).

Phillips, R. J., et al., "Hydrodynamic Transport Properties of Hard-Sphere Dispersions. I. Suspensions of Freely Mobile Particles," Physics of Fluids 31, 3462-72 (1988).

Wajnryb, E., and J. S. Dahler, "The Newtonian Viscosity of a Moderately Dense Suspension," in Advances in Chemical Physics, Vol. 102 (1997).

\section{SETTLING}

Koch, D. L., et al., "The Instability of a Dispersion of Sedimenting Spheroids," Journal of Fluid Mechanisms 209, 521-42 (1989).

Shaheen, E. I., "Rheological Study of Viscosities and Pipeline Flow of Concentrated Slurries," Thesis, The University of Tennessee, Knoxville, Tennessee, 1967.

Shor, J. T., and J. S. Watson, "The Sedimentation of Bimodal Distributions of Unflocculated Microspheres," Separation Science and Technology 25, 2157-70 (1990).

\section{RELATED MODELS}

Cronenberg, A. W., "Recent Developments in the Understanding of Energetic Molten Fuel Coolant Interactions," Nuclear Safety 21, 319-37 (1980).

Ottino, J. M., P. DeRoussel, S. Hansen, and D. V. Khakhar, "Mixing and Dispersion of Viscous Liquids and Powdered Solids," pp. 105-204 in Advances in Chemical Engineering, Vol. 25 (2000).

\section{GENERAL}

Hunter, R. J., Foundations of Colloid Science, Oxford University Press, Oxford, U.K., 2001.

Jou, D., J. Casas-Vázquez, and M. Criado-Sancho, Thermodynamics of Fluids Under Flow, Springer, Berlin, 2001. 
Monson, P. A., and D. A. Kofke, "Solid-Fluid Equilibrium: Insights from Simple Molecular Models," pp. 113-79 in Advances in Chemical Physics, Vol. 115, ed. I. Prigogine and S. Rice, John Wiley and Sons, Inc., New York, 2000.

Rosner, D. E., Transport Processes in Chemically Reacting Flow Systems, Butterworths, Boston, Mass., 1986. 



\section{APPENDIX A. THE GILLIES AND SHOOK CRITICAL VELOCITY CORRELATION}

Liddell and Burnett (2000) concluded that the Gillies and Shook (1991) equation was a possible candidate for waste pipeline design. This correlation was developed for slurries with a broad particle-size distribution (PSD), including the small particles of the homogeneous carrier fluid. The Gillies and Shook equation is as follows:

$$
F_{L}=\frac{v_{c}}{\left[\frac{2 g D\left(\rho_{s}-\rho_{f}\right)}{\rho_{f}}\right]^{1 / 2}}=\exp \left(0.165-0.073 C_{D}-12.5 K_{2}\right)
$$

where

$F_{L}=$ Froude number for deposition of a stationary bed;

$v_{c}=$ mean critical flow velocity;

$g=$ gravitational acceleration;

$D=$ pipe diameter;

$\rho_{s}=$ density of the solids;

$\rho_{f}=$ density of the carrier fluid,

$=\frac{\rho_{s} C_{f}+\left(1-C_{t}\right) \rho_{L}}{1-C_{t}+C_{r}} ;$

$C_{f}=$ solids volume fraction of $-74-\mu \mathrm{m}$ particles;

$C_{r}=$ solids volume fraction of $+74-\mu \mathrm{m}$ particles;

$C_{t}=$ solids volume fraction of total in situ solids,

$=C_{f}+C_{r}$

$C_{D}=$ drag coefficient for particles settling in an equivalent fluid of density, $\rho_{f}$, and viscosity, $\mu_{f}$;

$K_{2}=\left(K_{1}-0.14\right)^{2}$;

$K_{1}=\frac{\left(\frac{\mu_{L}}{\rho_{L}}\right)^{2 / 3}}{g^{1 / 3} d_{50}} ;$

$\mu_{L}=$ viscosity of the liquid;

$\rho_{L}=$ density of the liquid;

$d_{50}=$ mass median diameter of the coarse fraction $(+74 \mu \mathrm{m})$ of particles.

\section{A.1 REFERENCES}

Gilllies, R. G., and C. A. Shook. 1991. "A Deposition Velocity Correlation for Water Slurries," Canadian Journal of Chemical Engineering 69, 1225-27.

Liddell, K. C., and D. F. Burnett. 2000. Critical Transport Velocity: A Review of Correlations and Models, RPP-7185 Rev. 0, CH2MHILL Hanford Group, Richland, Washington (October). 



\section{APPENDIX B. THE TURBULENT EDDY FRACTION AND HINDERED SETTLING VELOCITY EQUATIONS FOR THE OROSKAR AND TURIAN CRITICAL VELOCITY CORRELATION}

The fraction of eddies with velocities exceeding the hindered settling velocity of the particles, $x$, derived by Oroskar and Turian (1980) is as follows:

$$
x=\frac{2}{\sqrt{\pi}}\left[\frac{2 \gamma}{\sqrt{\pi}} \exp \left(\frac{-4 \gamma^{2}}{\pi}\right)+\frac{\sqrt{\pi}}{2}\left(1-\operatorname{erf}\left(\frac{2 \gamma}{\sqrt{\pi}}\right)\right)\right] .
$$

In Eq. (B.1),

$$
\gamma=\frac{v_{s}}{v_{c}}
$$

where

$v_{c}=$ the critical velocity,

$v_{s}=$ the hindered settling velocity,

$$
=v_{\infty}(1-c)^{n} \text {. }
$$

In Eq. (B.3),

$c=$ the solids volume fraction,

$n=$ an empirical constant,

$=4.65$ as the particle Reynolds number approaches 0 ,

$=2.33$ for particle Reynolds number $\geq 1000$,

$v_{\infty}=$ the settling velocity of a spherical particle in a stagnant unbounded liquid.

See Julyk et al. (2000) for detailed example of the implementation for waste transfer system analysis.

\section{B.1 REFERENCES}

Oroskar, A. R., and R. M. Turian. 1980. “The Critical Velocity in Pipeline Flow of Slurries,” AIChE Journal 26(4), 550-58.

Julyk, L. J., J. C. Oten, and W. L. Willis. 2000. Waste Feed Delivery Transfer System Analysis, RPP-5346, CH2MHILL Hanford Group, Inc., Richland, Washington (May). 



\section{INTERNAL DISTRIBUTION}
1. J. M. Begovich
2. D. W. Depaoli
3. R. D. Hunt
4. R. T. Jubin
5. C. P. McGinnis
6. L. E. McNeese
7. S. M. Robinson

\author{
8. J. S. Watson \\ 9. C. F. Weber \\ 10-15. T. D. Welch \\ 16. ORNL Laboratory Records-OSTI \\ 17. ORNL Laboratory Records-RC \\ 18. Central Research Library
}

\section{EXTERNAL DISTRIBUTION}

19. H. Alhabbash, Diagnostic Instrumentation and Analysis Laboratory, 205 Research Boulevard, Starkville, MS 39759-9734

20. D. Baide, CH2M Hill Hanford Group, P.O. Box 1500, MSIN S7-90, Richland, WA 99352

21. B. Barton, CH2M Hill Hanford Group, P.O. Box 1500, MSIN R-11, Richland, WA 99352

22. J. Bell, 137 Bowsprit Lane, Kingston, TN 37763

23. N. Bhandari, Florida International University, 10555 West Flagler Street, CEAS 2100, Miami, FL 33174

24. K. Boomer, CH2M Hill Hanford Group, P.O. Box 1500, MSIN L4-07, Richland, WA 99352

25. B. Brendel, CH2M Hill Hanford Group, P.O. Box 1500, MSIN S7-90, Richland, WA 99352

26. J. Bryant, Pacific Northwest National Laboratory, P.O. Box 999, MSIN K7-94, Richland, WA 99352

27. W. Callaway, Cogema Engineering Corporation, P.O. Box 1000, MSIN T6-07, Richland, WA 99352

28. J. Cammann, CH2M Hill Hanford Group, P.O. Box 1500, MSIN T4-08, Richland, WA 99352

29. E. Carteret, Pacific Northwest National Laboratory, P.O. Box 999, MSIN K9-91, Richland, WA 99352

30. D. Crass, Numatec Hanford Corporation, P.O. Box 1300, MSIN S7-90, Richland, WA 99352

31. J. Cruz, Department of Energy, Office of River Protection, P.O. Box 550, MSIN H6-60, Richland, WA 99352

32. R. Edwards, Westinghouse Savannah River Company, Building 704-3N, Aiken, SC 29808

33. F. F. Erion, Pacific Northwest National Laboratory, P.O. Box 999, MSIN K7-15, Richland, WA 99352

34. S. Estey, CH2M Hill Hanford Group, P.O. Box 1500, MSIN R2-11, Richland, WA 99352

35. A. Felmy, Pacific Northwest National Laboratory, P.O. Box 999, MSIN K8-96, Richland, WA 99352

36. R. Fetterly, HND, 3250 Port of Benton Boulevard, Richland, WA 99352

37. K. Gasper, CH2M Hill Hanford Group, P.O. Box 1500, MSIN L4-07, Richland, WA 99352

38. P. Gauglitz, Pacific Northwest National Laboratory, P.O. Box 999, MSIN K6-28, Richland, WA 99352

39. D. Geniesse, Cogema Engineering Corporation, 2425 Stevens Drive, Richland, WA 99352

40. K. Gerdes, TFA Headquarters Program Lead, DOE Office of Science and Technology, 19901 Germantown Rd., 1154 Cloverleaf Building, Germantown, MD 20874-1290

41. P. Gibbons, Numatec Hanford Corporation, P.O. Box 1300, MSIN K9-91, Richland, WA 99352

42. R. Gilchrist, Pacific Northwest National Laboratory, P.O. Box 999, MSIN K9-91, Richland, WA 99352

43. S. Hailey, HND, 3250 Port of Benton Boulevard, Richland, WA 99352

44. J. Henshaw, AEA Technology, B220 Harwell, Didcot, Oxfordshire, UK, OX11 0RA

45. D. Herting, Fluor Hanford, P.O. Box 1000, MSIN T6-07, Richland, WA 99352

46. T. Hohl, Numatec Hanford Company, P.O. Box 1300, MSIN R3-73, Richland, WA 99352

47. J. Honeyman, CH2M Hill Hanford Group, P.O. Box 1500, MSIN H6-18, Richland, WA 99352 
48. J. Huckaby, Pacific Northwest National Laboratory, P.O. Box 999, MSIN K7-15, Richland, WA 99352

49. K. Hull, CH2M Hill Hanford Group, P.O. Box 1500, MSIN T4-07, Richland, WA 99352

50. J. Jewett, Numatec Hanford Company, P.O. Box 1300, MSIN R3-73, Richland, WA 99352

51. G. Josephson, Pacific Northwest National Laboratory, P.O. Box 999, MSIN K6-69, Richland, WA 99352

52. R. Kirkbride, Numatec Hanford Company, P.O. Box 1300, MSIN R3-73, Richland, WA 99352

53. J. Lindner, Diagnostic Instrumentation and Analysis Laboratory, 205 Research Boulevard, Starkville, MS 39759-9734

54. R. López, Florida International University, 10555 West Flagler St., CEAS 2100, Miami, FL 33174

55. R. Luyendijk, Waste Policy Institute, 2000 Craft Drive, Suite 1000, Blacksburg, VA 24060

56. G. MacLean, Fluor Federal Services, P.O. Box 1050, MSIN G3-10, Richland, WA 99352

57. B. Mauss, Department of Energy, Office of River Protection, P.O. Box 550, MSIN H6-60, Richland, WA 99352

58. P. Meyer, Pacific Northwest National Laboratory, P.O. Box 999, MSIN K7-15, Richland, WA 99352

59. J. Morin, Westinghouse Savannah River Co., 703-H Bldg./Rm. 119 Aiken, SC 29808

60. Y. Onishi, Pacific Northwest National Laboratory, P.O. Box 999, MSIN K7-15, Richland, WA 99352

61. R. Orme, Numatec Hanford Company, P.O. Box 1300, MSIN R3-73, Richland, WA 99352

62. J. Pike, Westinghouse Savannah River Co., Building 704-196N, Aiken, SC 29808

63. J. Plodinec, Diagnostic Instrumentation and Analysis Laboratory, 205 Research Boulevard, Starkville, MS 39759-9734

64. M. Poirier, Westinghouse Savannah River Company, Building 773-42A, Aiken, SC 29808

65. D. Reynolds, CH2MHILL Hanford Group, Inc, MSIN: R2-11, 2440 Stevens Center, P.O. Box 1500, Richland, WA 99352-1505

66. J. Roecker, 17123 North Brookside Lane, Colbert, WA 99005

67. W. Schulz, W2S Company, 12704 Sandia Ridge Place, NE, Albuquerque, NM 8711

68. R. Srivastava, Florida International University, 10555 West Flagler Street, CEAS 2100, Miami, FL 33174

69. L. Swanson, HND, 3250 Port of Benton Boulevard, Richland, WA 99352

70. Tanks Focus Area Headquarters Program Lead, c/o Kurt Gerdes, DOE Office of Science and Technology, 19901 Germantown Road, 1154 Cloverleaf Building, Germantown, MD 20874-1290

71. Tanks Focus Area Program Manager, c/o T.P. Pietrok, U.S. Department of Energy, Richland Operations Office, P.O. Box 550, MSIN K8-50, Richland, WA 99352

72. Tanks Focus Area Technical Team, c/o B.J. Williams, Pacific Northwest National Laboratory, P.O. Box 999, MSIN K9-69, Richland, WA 99352

73. L. Tavlarides, Syracuse University, Dept. of Chemical Engineering \& Materials Science, 334 Hinds Hall, Syracuse, NY 13244-1190

74. J. Thompson, Department of Energy, Office of River Protection, P.O. Box 550, MSIN H6-60, Richland, WA 99352

75. M. Thompson, Westinghouse Savannah River Company, Savannah River, Technology Center Building, 773-A, C140 Aiken, SC 29802

76. R. Thompson, CH2M Hill Hanford Group, P.O. Box 1500, MSIN T4-08, Richland, WA 99352

77. R. Toghiani, Mississippi State University, School of Chemical Engineering, P.O. Box 9595, MS State, MS 39762

78. G. Vandegrift, Argonne National Laboratory, Building 205, 9700 South Cass Avenue, Argonne, IL 60439

79. W. Warrant, Fluor Hanford, P.O. Box 1000, MSIN T6-07, Richland, WA 99352

80. F. Washburn, Westinghouse Savannah River Company, Building 704-196N, Aiken, SC 29808

81. T. Weber, 6622 West Victoria Avenue, Kennewick, WA 99336

82. J. Westsik Jr., Pacific Northwest National Laboratory, P.O. Box 999, MSIN K9-91, Richland, WA 99352

83. K. Wiemers, HND, 3250 Port of Benton Boulevard, Richland, WA 99352 